\title{
Recommended ideal-gas thermochemical functions for heavy water and its substituent isotopologues
}

Irén Simkó, ${ }^{1}$ Tibor Furtenbacher, ${ }^{2}$ Jan Hrubý, ${ }^{3}$ Nikolai F. Zobov, ${ }^{4}$ Oleg L. Polyansky, ${ }^{5}$ Jonathan Tennyson, ${ }^{5}$ Robert R. Gamache, ${ }^{6}$ Tamás Szidarovszky, ${ }^{2}$ Nóra Dénes, ${ }^{1}$ and Attila G. Császár*,7

1) Laboratory of Molecular Structure and Dynamics, Institute of Chemistry, Eötvös Loránd University, H-1532 Budapest, P.O. Box 32, Hungary

${ }^{2)}$ MTA-ELTE Complex Chemical Systems Research Group, H-1117 Budapest, Pázmány Péter sétány 1/A, Hungary

3) Institute of Thermomechanics of the CAS, v.v.i., Dolejškova 5, Prague 8, CZ-18200, Czech Republic

4) Institute of Applied Physics, Russian Academy of Science, Ulyanov Street 46, Nizhny Novgorod, Russia 603950

5) Department of Physics and Astronomy, University College London, Gower Street, London WC1E 6BT, United Kingdom

${ }^{6)}$ Department of Environmental, Earth, and Atmospheric Science, University of Massachusetts Lowell, 365 Riverside Street, Lowell, MA 01854 , U.S.A.

7)MTA-ELTE Complex Chemical Systems Research Group, H-1117 Budapest, Pázmány Péter sétány 1/A, Hungary, email: csaszarag@caesar.elte.hu 
Accurate temperature-dependent ideal-gas internal partition functions, $Q_{\text {int }}(T)$, and several derived thermochemical functions are reported for heavy water, with an oxygen content corresponding to the isotopic composition of the Vienna Standard Mean Ocean Water (VSMOW), and its constituent isotopologues, $\mathrm{D}_{2}{ }^{16} \mathrm{O}, \mathrm{D}_{2}{ }^{17} \mathrm{O}$, and $\mathrm{D}_{2}{ }^{18} \mathrm{O}$, for temperatures between 0 and $6000 \mathrm{~K}$. The nuclear-spin-dependent partition functions are obtained by the direct summation technique, involving altogether about 16000 measured and more than nine million computed bound rovibrational energy levels for the three molecules. Reliable standard uncertainties, as a function of temperature, are estimated for each thermochemical quantity determined, including the Gibbs energy function, the enthalpy, the entropy, and the isobaric heat capacity of the individual ortho and para nuclear-spin isomers, as well as of their nuclear-spin-equilibrated mixture and of heavy water. The accuracy of the heavy-water ideal-gas $C_{p}(T)$ is unprecedented, below $0.01 \%$ up to $1800 \mathrm{~K}$. All the thermochemical functions are reported, in $1 \mathrm{~K}$ increments, in the supplementary material to this paper.

Keywords: bound and unbound states; heavy water; ideal-gas thermochemical quantities; nuclear motion theory; partition function 


\section{Contents}

List of Tables $\quad 3$

$\begin{array}{ll}\text { List of Figures } & 4\end{array}$

$\begin{array}{ll}\text { 1. Introduction } & 5\end{array}$

2. Methodological Details 6

2.1. MARVEL energy levels $\quad 7$

2.2. First-principles energy levels $\quad 8$

2.3. The hybrid database $\quad 8$

2.4. Thermochemical quantities 10

2.5. Nuclear spin degeneracy factor 10

2.6. Uncertainty analysis 10

3. Results and Discussion 13

3.1. The partition and the thermochemical functions 13

3.2. Comparison with previous results 13

3.3. Isotopic composition of heavy water 15

3.4. Low-temperature limit 20

3.5. On the maximum in $C_{p} \quad 20$

$\begin{array}{ll}\text { 4. Summary and Conclusions } & 20\end{array}$

$\begin{array}{ll}\text { Acknowledgments } & 22\end{array}$

$\begin{array}{ll}\text { References } & 22\end{array}$

\section{List of Tables}

1 Uncertainties of the first-principles computed rovibrational energy levels of the three heavy-water isotopologues within the hybrid databases . . . . . . 7

2 Nuclear spin degeneracy factors of $\mathrm{D}_{2}{ }^{16} \mathrm{O}, \mathrm{D}_{2}{ }^{17} \mathrm{O}$, and $\mathrm{D}_{2}{ }^{18} \mathrm{O} \ldots \ldots \ldots \ldots \ldots$

3 The temperature-dependent nuclear-spin-equilibrated internal partition functions, $Q_{\text {int }}(T)$, of $\mathrm{D}_{2}{ }^{16} \mathrm{O}$ and its first two moments, $Q_{\text {int }}^{\prime}(T)$ and $Q_{\text {int }}^{\prime \prime}(T)$. The standard uncertainties associated with the data are given in parentheses. . . . 15

4 The temperature-dependent nuclear-spin-equilibrated internal partition functions, $Q_{\text {int }}(T)$, of $\mathrm{D}_{2}{ }^{17} \mathrm{O}$ and its first two moments, $Q_{\text {int }}^{\prime}(T)$ and $Q_{\text {int }}^{\prime \prime}(T)$. The standard uncertainties associated with the data are given in parentheses. . . . . 
5 The temperature-dependent nuclear-spin-equilibrated internal partition functions, $Q_{\text {int }}(T)$, of $\mathrm{D}_{2}{ }^{18} \mathrm{O}$ and their first two moments, $Q_{\text {int }}^{\prime}(T)$ and $Q_{\text {int }}^{\prime \prime}(T)$. The standard uncertainties associated with the data are given in parentheses. . . . 17

6 Thermochemical functions of $\mathrm{D}_{2}{ }^{16} \mathrm{O}, \mathrm{D}_{2}{ }^{17} \mathrm{O}$, and $\mathrm{D}_{2}{ }^{18} \mathrm{O}$; the standard uncertainties associated with the data are given in parentheses. . . . . . . . . . 18

7 The $Q_{\text {int }}(T)$ partition function and the $C_{p}(T)$ isobaric heat capacity of heavy water determined in this study. . . . . . . . . . . . . . . . . .

\section{List of Figures}

1 Ratio of the $\mathrm{D}_{2}{ }^{16} \mathrm{O}$ and $\mathrm{D}_{2}{ }^{17} \mathrm{O}$ (left panel) and $\mathrm{D}_{2}{ }^{16} \mathrm{O}$ and $\mathrm{D}_{2}{ }^{18} \mathrm{O}$ (right panel) energy levels as a function of the rotational quantum number $J$.

2 The individual uncertainty contributions of $Q_{\text {int }}(T)$ (left panel) and $C_{p}(T)$ (right panel) of $\mathrm{D}_{2}{ }^{16} \mathrm{O}$ (first row), $\mathrm{D}_{2}{ }^{17} \mathrm{O}$ (second row), and $\mathrm{D}_{2}{ }^{18} \mathrm{O}$ (third row). 12

3 Comparison of the present $Q_{\text {int }}(T)$ values of $\mathrm{D}_{2}{ }^{16} \mathrm{O}$ with those of Hewitt et $a l$., defined with respect to the present values.

4 Comparison of the present $C_{p}(T)$ values of $\mathrm{D}_{2}{ }^{16} \mathrm{O}$ with those of Friedman and Haar (FH) (full, black curve) and Martin et al. (dashed, red curve). . . . . . 14

5 The ortho- $\mathrm{D}_{2}{ }^{16} \mathrm{O}$ (dashed, red curve), the para- $\mathrm{D}_{2}{ }^{16} \mathrm{O}$ (full, black curve), the nuclear-spin-equilibrated $\mathrm{D}_{2}{ }^{16} \mathrm{O}$ (magenta, dotted curve), and the normal mixture $\mathrm{D}_{2}{ }^{16} \mathrm{O}$ (blue, dash dotted curve) isobaric heat capacities at low

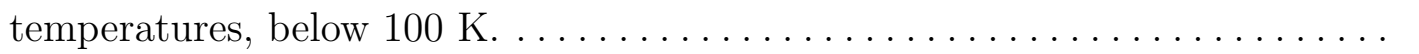




\section{Introduction}

Despite the low cosmological abundance of deuterium, $\mathrm{D}_{2}{ }^{16} \mathrm{O}$ has been detected in the interstellar medium. ${ }^{1} \mathrm{D}_{2}{ }^{16} \mathrm{O}$ is particularly prevalent in the environments of low-mass starforming regions, where its gas-phase abundance can be surprisingly large ${ }^{2}$ and where analysis of ratios of ortho and para species point to formation at very low temperatures. ${ }^{3}$ Fractionation effects are important for the production of $\mathrm{D}_{2}{ }^{16} \mathrm{O}$ in these environments. ${ }^{4-6}$ On earth, $\mathrm{D}_{2} \mathrm{O}$ is used as a substitute for ordinary water in various fields of science and technology utilizing neutron scattering and related experimental and testing techniques. Following the recommendation of the International Association for the Properties of Water and Steam (IAPWS,${ }^{7}$ "heavy water" is defined ${ }^{8}$ here as "water whose hydrogen content is pure ${ }^{2} \mathrm{H}$ and whose oxygen has the isotopic composition of the Vienna Standard Mean Ocean Water (VSMOW)". ${ }^{9-11}$ The terrestrial and extraterrestrial applications mentioned often require knowledge of a range of thermodynamic properties of heavy water as well as of its constituent isotopologues. The thermodynamic properties of heavy water have particular importance in the nuclear power industry. ${ }^{12-14}$ Consequently, IAPWS ${ }^{7}$ developed an international standard equation of state (EOS) for the thermodynamic properties of heavy water and adopted it in 1984. This EOS is based on a publication of Hill et al. ${ }^{13}$ who fitted a polynomial to the ideal-gas heat capacity of heavy water calculated by Friedman and Haar (FH) in $1954 .{ }^{15}$ Although the 1984 IAPWS recommendation was slightly revised in $2005,{ }^{16}$ to make the old equation conform to the ITS-90 ${ }^{17}$ temperature scale, it kept employing the ideal-gas FH data. The results of $\mathrm{FH}^{15}$ form also the basis of the JANAF (Joint Army, Navy, and Air Force) tables of $\mathrm{D}_{2}{ }^{16} \mathrm{O} .{ }^{18}$ The dimensionless data of $\mathrm{FH}^{15}$ have been converted to become the JANAF tables using a universal molar gas constant $R=8.31441(26) \mathrm{J} \mathrm{mol}^{-1} \mathrm{~K}^{-1}$, the value of this physical constant available in $1973 .{ }^{19}$ Furthermore, the $\mathrm{FH}$ data for isobaric heat capacities between 4000 and $5000 \mathrm{~K}$ were extrapolated linearly (except with a term in $T^{-2}$ ) to obtain the JANAF data up to $6000 \mathrm{~K}$. JANAF can be considered as the most widely employed present-day general reference for thermochemical data.

Any standard EOS requires a formulation of the ideal-gas thermodynamic functions in order to compute properties of the real fluid, such as heat capacity, enthalpy, and entropy (sometimes called "caloric properties"), as well as properties such as the speed of sound in the given phase and the Joule-Thomson coefficient. ${ }^{20}$ The EOS is typically written as a function of temperature and density. Part of the EOS is based on the ideal-gas contribution depending on properties of single molecules, while the residual part reflects intermolecular interactions. The ideal-gas contribution to the EOS requires an expression for the isobaric heat capacity of the ideal gas.

In 2012, IAPWS began an effort to develop a new heavy-water standard, which would take advantage of recent developments in EOS methodology and of new data. Since our molecular knowledge of heavy water, and therefore our ability to compute its ideal-gas thermodynamics, has greatly advanced compared to 1954, it is highly desirable to have new, 
more accurate ideal-gas heat-capacity values to use in the new formulation. An inaccurate ideal-gas heat capacity would force the other fitted terms in the EOS to be distorted in order to fit experimental data for caloric properties. It is also desirable to have good estimates of the uncertainty in these heat capacities, in order to estimate the uncertainty in caloric properties calculated from the EOS - the uncertainty of the $\mathrm{FH}^{15}$ results is unclear and $\mathrm{FH}$ did not provide quantitative uncertainty estimates. Moreover, a clear disadvantage of the FH calculations is that they only concern $\mathrm{D}_{2}{ }^{16} \mathrm{O}$, the most abundant heavy-water constituent. Clearly, both the IAPWS and the JANAF heavy-water data are ready for a substantial revision.

Several of the present authors published a study in this journal on the determination of highly accurate ideal-gas thermochemical functions for $\mathrm{H}_{2}{ }^{16} \mathrm{O}$ between 0 and $6000 \mathrm{~K} .{ }^{21}$ In that study, hereafter referred to as $\mathbf{I}$, it was shown that a limited set of highly accurate experimental rovibrational energy levels combined with a full set of first-principles computed energy levels up to (and beyond) dissociation provides the basis for highly accurate ideal-gas thermochemical functions up to rather high temperatures, $6000 \mathrm{~K}$ being the reported limit. For $\mathrm{H}_{2}{ }^{16} \mathrm{O}$ the uncertainty in the internal partition function, $Q_{\text {int }}(T)$, below $600 \mathrm{~K}$, where all the rovibrational energy levels needed to compute a fully converged $Q_{\text {int }}(T)$ are available experimentally, is less than $10^{-4} \%$. The uncertainty grows slowly as the temperature increases. Some of the present authors have also been involved in the determination of experimental rotational-vibrational energy levels on the ground electronic states of $\mathrm{D}_{2}{ }^{16} \mathrm{O}$, $\mathrm{D}_{2}{ }^{17} \mathrm{O}$, and $\mathrm{D}_{2}{ }^{18} \mathrm{O} .{ }^{22}$ Hereby, in response to the interest in improving the quality of the IAPWS and JANAF data, we extend the ideal-gas thermochemical study of $\mathrm{H}_{2}{ }^{16} \mathrm{O}$ to three deuterated isotopologues of water, $\mathrm{D}_{2}{ }^{16} \mathrm{O}, \mathrm{D}_{2}{ }^{17} \mathrm{O}$, and $\mathrm{D}_{2}{ }^{18} \mathrm{O}$, which must be considered during the computation of thermodynamic properties of heavy water in the ideal-gas state.

Finally, note that there are only a very limited number of studies ${ }^{15,23-25}$ known to us on the ideal-gas $Q_{\text {int }}(T)$ and related thermochemical functions of any of the three heavy-water isotopologues. None of these studies come close to the accuracy of the present investigation, which heavily builds upon achievements in the fourth age of quantum chemistry. ${ }^{26}$

\section{Methodological Details}

In what follows we compute ideal-gas thermochemical functions for the three isotopologues of heavy water employing a protocol advocated in I. According to that recommendation, two types of rovibrational energy level sets are utilized for computing $Q_{\text {int }}(T)$ for $\mathrm{D}_{2}{ }^{16} \mathrm{O}$, $\mathrm{D}_{2}{ }^{17} \mathrm{O}$, and $\mathrm{D}_{2}{ }^{18} \mathrm{O}$. The first data set comprises all the available experimental energy levels, obtained via a measured active rotational-vibrational energy levels (MARVEL) ${ }^{27-29}$ analysis of the experimental rovibrational transitions, ${ }^{22}$ while the second data set contains first-principles computed levels determined as part of the present study. 
Table 1. Uncertainties of the first-principles computed rovibrational energy levels of the three heavy-water isotopologues within the hybrid databases

\begin{tabular}{|c|c|c|c|}
\hline Molecule & PES & Energy range $/ \mathrm{cm}^{-1}$ & Uncertainty $/ \mathrm{cm}^{-1}$ \\
\hline \multirow[t]{9}{*}{$\mathrm{D}_{2}{ }^{16} \mathrm{O}$} & PES-S ${ }^{30}$ & $0-3000$ & 0.1 \\
\hline & & $3000-5000$ & 0.5 \\
\hline & & $5000-15000$ & 1.0 \\
\hline & PES-P 31 & $0-15000$ & 2.0 \\
\hline & & $15000-25000$ & 5.0 \\
\hline & & $25000-30000$ & 10.0 \\
\hline & & $30000-35000$ & 100.0 \\
\hline & & $35000-40000$ & 250.0 \\
\hline & & above 40000 & 500.0 \\
\hline \multirow[t]{9}{*}{$\mathrm{D}_{2}{ }^{17} \mathrm{O}, \mathrm{D}_{2}{ }^{18} \mathrm{O}$} & PES-S ${ }^{30}$ & 0-3000 & 0.1 \\
\hline & & $3000-5000$ & 0.5 \\
\hline & & $5000-15000$ & 1.0 \\
\hline & PES-P 31 & $0-15000$ & 3.0 \\
\hline & & $15000-25000$ & 7.5 \\
\hline & & $25000-30000$ & 15.0 \\
\hline & & $30000-35000$ & 150.0 \\
\hline & & $35000-40000$ & 375.0 \\
\hline & & above 40000 & 750.0 \\
\hline
\end{tabular}

\subsection{MARVEL energy levels}

The most complete and probably most accurate source of bound measured rovibrational energy levels of $\mathrm{D}_{2}{ }^{16} \mathrm{O}, \mathrm{D}_{2}{ }^{17} \mathrm{O}$, and $\mathrm{D}_{2}{ }^{18} \mathrm{O}$ is the MARVEL database, ${ }^{22,32}$ obtained as part of an IUPAC-sponsored research effort. ${ }^{22,33-36}$ The number of validated energy levels in the published IUPAC database of measured rovibrational transitions and energy levels is 12 269, 338 , and 3351 for $\mathrm{D}_{2}{ }^{16} \mathrm{O}, \mathrm{D}_{2}{ }^{17} \mathrm{O}$, and $\mathrm{D}_{2}{ }^{18} \mathrm{O}$, respectively. The uncertainty of the MARVEL energy levels is between $10^{-6}$ and $10^{-2} \mathrm{~cm}^{-1}$, each energy level carries its own uncertainty.

The labeling scheme employed for the rovibrational states of the $\mathrm{D}_{2} \mathrm{O}$ isotopologues employs six quantum numbers: $v_{1}, v_{2}$, and $v_{3}$ are approximate normal-mode quantum numbers describing the vibrations (symmetric stretch, bend, and antisymmetric stretch, respectively), while the exact $J$ rotational quantum number and the approximate $K_{\mathrm{a}}$ and $K_{\mathrm{c}}$ values are used for the description of the rotations. ${ }^{37}$ 


\subsection{First-principles energy levels}

The first-principles bound rovibrational energy levels of the three isotopologues of heavy water utilized in this study were computed using two different potential energy surfaces (PES). For all three isotopologues, we used the best, semi-theoretical heavy-water PES, ${ }^{30}$ hereby called PES-S, and the D2FOPI ${ }^{38}$ variational nuclear-motion code to obtain the bound rovibrational energy levels up to $15000 \mathrm{~cm}^{-1}$ and/or up to $J=40$. The reason to employ this cutoff value is that the accurate, empirical PES-S was fitted only up to this value and it does not dissociate correctly.

In the case of $\mathrm{D}_{2}{ }^{16} \mathrm{O}$, the PoKaZaTeL global adiabatic PES, ${ }^{31}$ developed for $\mathrm{H}_{2}{ }^{16} \mathrm{O}$ and hereby called PES-P, and the DVR3D nuclear-motion code ${ }^{39}$ were used to determine all bound rovibrational energy levels up to the first dissociation limit $\left(D_{0}=41864.7 \mathrm{~cm}^{-1}\right) .{ }^{40}$ This data set contains slightly more than 3000000 energy levels and the largest rotational quantum number is $J=98$. The accuracy of the energy levels computed with PES-P for $\mathrm{H}_{2}{ }^{16} \mathrm{O}$, for which it was developed, is better, on average, than $1 \mathrm{~cm}^{-1}$, even near the first dissociation limit. We could expect a similar though lower level of accuracy for the $\mathrm{D}_{2}{ }^{16} \mathrm{O}$ levels when using PES-P if the variational nuclear motion computations were highly converged (the kinetic energy operator employed is exact within the Born-Oppenheimer approximation). However, for the calculation of partition functions we do not need the same high level of accuracy as required for spectroscopic problems, especially not for the high-lying states (though we must ensure ${ }^{21}$ that the correct number of states is involved during the direct evaluation of the internal partition function). The converged computations of the $\mathrm{H}_{2}{ }^{16} \mathrm{O}$ bound-state rovibrational energy levels with $J=0-68$ took several months of supercomputer time. ${ }^{31}$ For $\mathrm{D}_{2}{ }^{16} \mathrm{O}$, the dissociation energy is somewhat larger and the maximum $J$ value at which computations are required, as well as the level density, are much higher than for $\mathrm{H}_{2}{ }^{16} \mathrm{O}$. To perform the computations of $\mathrm{D}_{2}{ }^{16} \mathrm{O}$ in a reasonable amount of time, with an accuracy deemed sufficient for the determination of the partition function, we chose to use different basis sets during the DVR3D computations for the different $J$ values. With increasing $J$ and increase of the energy we decreased the size of the basis and thus decreased the accuracy of the computed levels. Note that the energy levels with $J>75$ were computed with a version of the DVR3D and ROTLEV programs modified to do high- $J$ computations. ${ }^{41,42}$

Table 1 lists the average accuracies, representing two standard deviations, estimated for the different energy regions for $\mathrm{D}_{2}{ }^{16} \mathrm{O}, \mathrm{D}_{2}{ }^{17} \mathrm{O}$, and $\mathrm{D}_{2}{ }^{18} \mathrm{O}$ for the two PESs.

\subsection{The hybrid database}

To ensure the highest possible accuracy of our energy level sets, we replaced the firstprinciples energy levels with MARVEL energies whenever it is possible and this way we obtain what is called hereafter the hybrid database. 

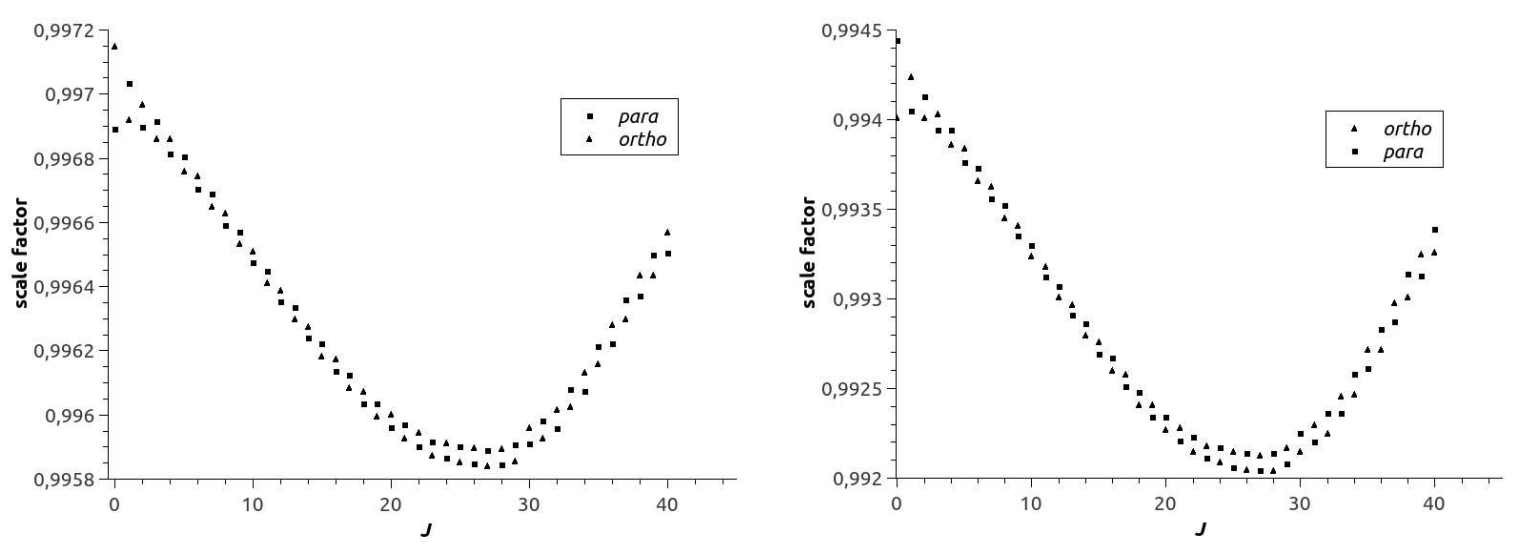

Figure 1. Ratio of the $\mathrm{D}_{2}{ }^{16} \mathrm{O}$ and $\mathrm{D}_{2}{ }^{17} \mathrm{O}$ (left panel) and $\mathrm{D}_{2}{ }^{16} \mathrm{O}$ and $\mathrm{D}_{2}{ }^{18} \mathrm{O}$ (right panel) energy levels as a function of the rotational quantum number $J$.

In case of $\mathrm{D}_{2}{ }^{17} \mathrm{O}$ and $\mathrm{D}_{2}{ }^{18} \mathrm{O}$, due to the lack of explicitly computed energies above 15000 $\mathrm{cm}^{-1}$, we need to determine an approximate rovibrational energy level set beyond this energy. We decided to employ for this purpose the $\mathrm{D}_{2}{ }^{16} \mathrm{O}$ energy levels computed with PES-P. We calculate the ratio between the $\mathrm{D}_{2}{ }^{16} \mathrm{O}$ and $\mathrm{D}_{2}{ }^{17} \mathrm{O}$, and the $\mathrm{D}_{2}{ }^{16} \mathrm{O}$ and $\mathrm{D}_{2}{ }^{18} \mathrm{O}$ energy levels as a function of $J$, up to $J=40$. The left and the right panels of Figure 1 show the ratios as a function of $J$ for $\mathrm{D}_{2}{ }^{17} \mathrm{O}$ and $\mathrm{D}_{2}{ }^{18} \mathrm{O}$, respectively. As $J$ is a good quantum number available from the first-principles computations, these ratios can be used to scale the $\mathrm{D}_{2}{ }^{16} \mathrm{O}$ energy levels and obtain those of $\mathrm{D}_{2}{ }^{17} \mathrm{O}$ and $\mathrm{D}_{2}{ }^{18} \mathrm{O}$. As expected, the scale factors are close to 1.0 for both isotopologues.

Above $J=40$, we use an average factor to scale the $\mathrm{D}_{2}{ }^{16} \mathrm{O}$ energy levels to obtain the corresponding levels of $\mathrm{D}_{2}{ }^{17} \mathrm{O}$ and $\mathrm{D}_{2}{ }^{18} \mathrm{O}$. We scale the energies not only below but also above the $D_{0}$ of $\mathrm{D}_{2}{ }^{16} \mathrm{O}$, so that more bound states are obtained up to the first dissociation limit for $\mathrm{D}_{2}{ }^{17} \mathrm{O}$ and $\mathrm{D}_{2}{ }^{18} \mathrm{O}$ than for $\mathrm{D}_{2}{ }^{16} \mathrm{O}$. Ref. 43 gives $D_{0}$ values for all isotopologues of water, the $D_{0}$ values employed here for $\mathrm{D}_{2}{ }^{17} \mathrm{O}$ and $\mathrm{D}_{2}{ }^{18} \mathrm{O}$ were obtained by correcting $D_{0}$ of $\mathrm{D}_{2}{ }^{16} \mathrm{O}$ of Ref. 40 with differences calculated in Ref. 43 , yielding $D_{0}\left(\mathrm{D}_{2}{ }^{17} \mathrm{O}\right)=41869$ and $D_{0}\left(\mathrm{D}_{2}{ }^{18} \mathrm{O}\right)=41873 \mathrm{~cm}^{-1}$. The average scale factors used are 0.996283 and 0.992842 for $\mathrm{D}_{2}{ }^{17} \mathrm{O}$ and $\mathrm{D}_{2}{ }^{18} \mathrm{O}$, respectively. Using the average scale factors we finally arrived at 3013166 and 3038803 rovibrational energy levels for $\mathrm{D}_{2}{ }^{17} \mathrm{O}$ and $\mathrm{D}_{2}{ }^{18} \mathrm{O}$, respectively. The final $\mathrm{D}_{2}{ }^{16} \mathrm{O}, \mathrm{D}_{2}{ }^{17} \mathrm{O}$, and $\mathrm{D}_{2}{ }^{18} \mathrm{O}$ hybrid databases contain 3055717,3084 456, and 3110893 energy levels up to $J=98$, respectively.

This procedure does not ensure that we have the complete set of rovibrational states very close to the dissociation limit. This minor shortcoming of the present treatment is reflected in the somewhat increased uncertainties at the highest temperatures for $\mathrm{D}_{2}{ }^{17} \mathrm{O}$ and $\mathrm{D}_{2}{ }^{18} \mathrm{O}$ (note the large uncertainties employed for energy levels above $35000 \mathrm{~cm}^{-1}$, Table 1). 


\subsection{Thermochemical quantities}

As usual, ${ }^{20,44-46}$ the total partition function is assumed to be the product of the internal and the translational partition functions. As also well known, ${ }^{23,47}$ the internal partition function, $Q_{\text {int }}$, of a free molecule is written as

$$
Q_{\mathrm{int}}=g_{\mathrm{s}} \sum_{i} g_{i}\left(2 J_{i}+1\right) \exp \left(\frac{-c_{2} E_{i}}{T}\right)
$$

where $c_{2}=h c / k_{\mathrm{B}}$ is the second radiation constant, $J_{i}$ is the rotational quantum number, $E_{i}$ is the rotational-vibrational energy level given in $\mathrm{cm}^{-1}$ (the zero is taken as the ground vibrational state), $T$ is the thermodynamic temperature in $\mathrm{K}, g_{\mathrm{s}}$ is a state-independent nuclear-spin degeneracy factor for atoms not exchanged under rotation, ${ }^{45} g_{i}$ is the nuclearspin degeneracy factor for identical atom interchanged under rotation, and the index $i$ runs over all possible rovibronic energies considered. The definitions of further thermochemical functions and the numerical values of the constants employed in this study can be found in $\mathbf{I}$. Values of the molecular masses used in this study are $3.324916944 \times 10^{-26} \mathrm{~kg}, 3.491671120$ $\times 10^{-26} \mathrm{~kg}$, and $3.657729650 \times 10^{-26} \mathrm{~kg}$ for $\mathrm{D}_{2}{ }^{16} \mathrm{O}_{\mathrm{D}_{2}}{ }^{17} \mathrm{O}$ and $\mathrm{D}_{2}{ }^{18} \mathrm{O}$, respectively.

\subsection{Nuclear spin degeneracy factor}

In the case of a triatomic molecule where two identical nuclei can be exchanged, like the case of the three isotopologues of heavy water, there are two separate rovibrational energy level sets corresponding to two distinct molecules. The two sets are called ortho and para. These distinct principal components of the spectroscopic network $(\mathrm{SN})^{48,49}$ of the molecule cannot be connected by transitions measured by traditional techniques of high-resolution spectroscopy. As emphasized in the previous subsection, the nuclear spin statistics, and consequently the degeneracy, factors of Eq. (1) also depend on the nuclear spin $I$ of the non-commuting nucleus. In the present case, the $\mathrm{D}$ nucleus is a boson with spin 1 and $I\left({ }^{16} \mathrm{O}\right)=I\left({ }^{18} \mathrm{O}\right)=0$ and $I\left({ }^{17} \mathrm{O}\right)=5 / 2$, explaining the degeneracy factors of Table 2.

Note that for the three $\mathrm{D}_{2} \mathrm{O}$ isotopologues, due to the fact that $I(\mathrm{D})=1$, the ground, $J=0$ state is ortho (with one of six symmetric spin states, $I=0$ or 2 ) and $J_{K_{a} K_{c}}=1_{01}$ is the lowest-energy rotational state of para symmetry (with one of three antisymmetric spin states, $I=1)$. At the lowest temperatures the equilibrium composition $\left(e-\mathrm{D}_{2} \mathrm{O}\right)$ is pure ortho, and for "normal" $\mathrm{D}_{2} \mathrm{O}\left(n-\mathrm{D}_{2} \mathrm{O}\right)$, where "normal" means the equilibrated composition at the high-temperature limit, the ortho-para ratio (OPR) is 2:1.

\subsection{Uncertainty analysis}

We just briefly summarize the most important sources of uncertainty of the computed thermochemical functions, identified in $\mathbf{I}$, before going into a detailed uncertainty quantification analysis for the isobaric heat capacity. 
Table 2. Nuclear spin degeneracy factors of $\mathrm{D}_{2}{ }^{16} \mathrm{O}, \mathrm{D}_{2}{ }^{17} \mathrm{O}$, and $\mathrm{D}_{2}{ }^{18} \mathrm{O}$.

\begin{tabular}{lcc}
\hline \hline Molecule & Spectroscopic notation $^{a}$ & Degeneracy factor \\
\hline ortho- $\mathrm{D}_{2}{ }^{16} \mathrm{O}$ & $v_{3}+K_{\mathrm{a}}+K_{\mathrm{c}}$ even & 6 \\
para $-\mathrm{D}_{2}{ }^{16} \mathrm{O}$ & $v_{3}+K_{\mathrm{a}}+K_{\mathrm{c}}$ odd & 3 \\
ortho- $\mathrm{D}_{2}{ }^{17} \mathrm{O}$ & $v_{3}+K_{\mathrm{a}}+K_{\mathrm{c}}$ even & 36 \\
para $-\mathrm{D}_{2}{ }^{17} \mathrm{O}$ & $v_{3}+K_{\mathrm{a}}+K_{\mathrm{c}}$ odd & 18 \\
ortho- $\mathrm{D}_{2}{ }^{18} \mathrm{O}$ & $v_{3}+K_{\mathrm{a}}+K_{\mathrm{c}}$ even & 6 \\
para $-\mathrm{D}_{2}{ }^{18} \mathrm{O}$ & $v_{3}+K_{\mathrm{a}}+K_{\mathrm{c}}$ odd & 3 \\
\hline \hline
\end{tabular}

${ }^{a} v_{3}$ is the antisymmetric OD stretch quantum number, $K_{\mathrm{a}}$ and $K_{\mathrm{c}}$ are the standard asymmetric-top rotational quantum numbers.

Figure 2 shows the individual uncertainty contributions of $Q_{\text {int }}(T)$ (left panel) and $C_{p}(T)$ (right panel) in the case of the heavy water isotopologues. It can be seen that above 4500 $\mathrm{K}$ the largest uncertainty of $C_{p}(T)$ comes from the consideration of the unbound states. In $\mathbf{I}$ the contribution of the unbound states was estimated based on a simple model which overestimated this contribution by a factor of around two for bound states and a similar overestimation was assumed for the unbound states. In this study we employed the same technique to determine the contribution of the unbound states of the $\mathrm{D}_{2}{ }^{16} \mathrm{O}$ molecule. Since this technique most likely overestimates the uncertainty contribution, we used the results of $\mathrm{D}_{2}{ }^{16} \mathrm{O}$ molecule in cases of $\mathrm{D}_{2}{ }^{17} \mathrm{O}$ and $\mathrm{D}_{2}{ }^{18} \mathrm{O}$. Furthermore, the uncertainty of the contribution was assumed to be the same as its value. This type of uncertainty is close to zero up to $4000 \mathrm{~K}$, but above this temperature this contribution dominates. The situation is different in the case of $Q_{\text {int }}(T)$, where the largest source of uncertainty (almost in the whole temperature range) is the uncertainty of the energy levels.

We employed the "two extrema" method (see I) to determine the uncertainty of the partition function (and the thermochemical functions) which comes from the uncertainty of the energy levels. We also determined this type of uncertainty using the common error propagation formula, but since the uncertainty of the energy levels of the heavy-water molecules are much larger than the uncertainty of energy levels of $\mathrm{H}_{2}{ }^{16} \mathrm{O}$, the analytical formula provided artificially small uncertainties. Figure 2 shows that this type of uncertainty is smaller than $0.5 \%$ even at high temperatures. In the case of $Q_{\text {int }}(T)$, this contribution is the dominant part of the total uncertainty in the whole temperature range (except for $\mathrm{D}_{2}{ }^{16} \mathrm{O}$ above 5500 $\mathrm{K}$ ), since the uncertainties of the first-principles computed energy levels are considerably larger (see Table 1 ). In the case of $C_{p}(T)$ this type of uncertainty is almost negligible above $5000 \mathrm{~K}$.

The third type of uncertainty is the uncertainty about the number of bound energy levels. We estimated this type of uncertainty with the differences of the $Q_{\text {int }}^{\text {tot }}$ and $Q_{\text {int }}^{\text {cutoff }}$ where the 

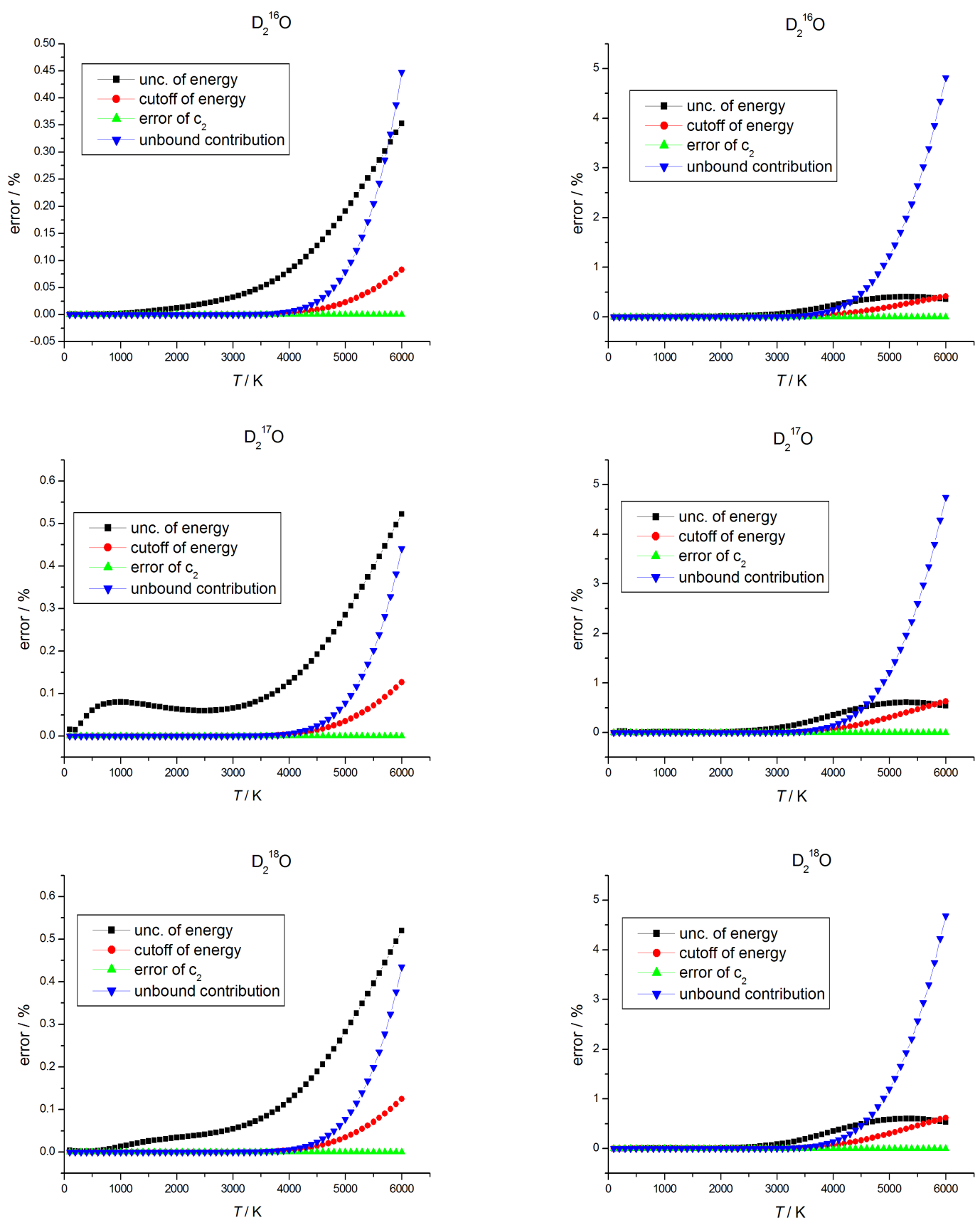

Figure 2. The individual uncertainty contributions of $Q_{\text {int }}(T)$ (left panel) and $C_{p}(T)$ (right panel) of $\mathrm{D}_{2}{ }^{16} \mathrm{O}$ (first row), $\mathrm{D}_{2}{ }^{17} \mathrm{O}$ (second row), and $\mathrm{D}_{2}{ }^{18} \mathrm{O}$ (third row).

cutoff value (i.e., the inclusion of the energy levels only up this value) is $D_{0}-500 \mathrm{~cm}^{-1}$ in the case of $\mathrm{D}_{2}{ }^{16} \mathrm{O}$, and $D_{0}-750 \mathrm{~cm}^{-1}$ for the other two isotopologues (i.e., we reduced the dissociation limit with the largest uncertainty). Figure 2 shows that this type of uncertainty is also smaller than $0.5 \%$ and it is negligible under $4000 \mathrm{~K}$.

The fourth source of uncertainty in computed thermochemical functions comes from the uncertainties of the physical constants employed. Although such uncertainties are usually 
considered to be negligible, the uncertainty of $c_{2}\left(1.43877736(83) \times 10^{-2} \mathrm{~m} \mathrm{~K}\right)$ cannot simply be neglected, as shown in $\mathbf{I}$. But in the case of the heavy-water isotopologues, the effect of the uncertainty of $c_{2}$ is negligible even at lower temperatures, since (a) the MARVEL database of the heavy-water molecules is not as complete as the MARVEL database of $\mathrm{H}_{2}{ }^{16} \mathrm{O}$, so there are first-principles computed energy levels (with sizeable uncertainties) at relatively low energies, and (b) the uncertainties of the experimental energy levels are larger in the case of heavy water than they are for $\mathrm{H}_{2}{ }^{16} \mathrm{O}$. An adjustment of $C_{p}(T)$ in case that the value of $R$ and $c_{2}$ are changed is

$$
C_{p, \text { new }}(T)=C_{p, \text { old }}(T)\left[\frac{R_{\text {new }}}{R_{\text {old }}}-\frac{\partial \ln C_{p}}{\partial \ln T}\left(\frac{c_{2, \text { new }}}{c_{2, \text { old }}}-1\right)\right] .
$$

The dependence of our computed heat capacity values on the uncertainty of $R$ can be masked by reporting $C_{p}(T) / R$ values. This practice is followed in the present study. However, it is to be noted that the values of the second radiation constant $c_{2}$ are very closely correlated to $R$ and, consequently, any change of $R$ must be accompanied by a corresponding adjustment of $c_{2}$. As a consequence of the close covariance of $R$ and $c_{2}$, a simple form can be derived for the combined contribution of the uncertainties of $c_{2}$ and $R$ to the standard uncertainty of $C_{p}$,

$$
\left|1+\frac{\partial \ln C_{p}}{\partial \ln T}\right| u_{r}(R) C_{p}
$$

where $u_{r}(R)$ is the relative standard uncertainty of the universal gas constant. In the proposed re-definition of the SI system, ${ }^{50}$ both $R$ and $c_{2}$ will become exact constants and their uncertainties will be transformed into the uncertainty of the temperature scale.

\section{Results and Discussion}

\subsection{The partition and the thermochemical functions}

The values of $Q_{\text {int }}, Q_{\text {int }}^{\prime}$, and $Q_{\text {int }}^{\prime \prime}$ of $\mathrm{D}_{2}{ }^{16} \mathrm{O}, \mathrm{D}_{2}{ }^{17} \mathrm{O}$, and $\mathrm{D}_{2}{ }^{18} \mathrm{O}$ are presented in Tables $3-5$, respectively, in $100 \mathrm{~K}$ intervals up to $6000 \mathrm{~K}$. The full set of results at $1 \mathrm{~K}$ increments is given in the supplementary material ${ }^{51}$ to this paper. Table 6 lists the following thermochemical functions at different temperatures for the three isotopologues: isobaric heat capacity, $C_{p}(T)$, entropy, $S(T)$, and standard enthalpy, $H^{\mathrm{o}}(T)$. The supplementary material ${ }^{51}$ also contains the same information for the ortho and para forms of the three isotopologues and the most important thermochemical functions, all at $1 \mathrm{~K}$ increments.

\subsection{Comparison with previous results}

Figure 2 shows the difference between our $\mathrm{D}_{2}{ }^{16} \mathrm{O} Q_{\text {int }}(T)$ partition function and that of Hewitt et al. ${ }^{24}$ who only considered temperatures below $1000 \mathrm{~K}$. At low temperatures the agreement between the two studies is excellent although it would appear that Hewitt et al.'s calculations give a partition function which is too low above about $600 \mathrm{~K}$, probably due to incomplete lists of energy levels. 


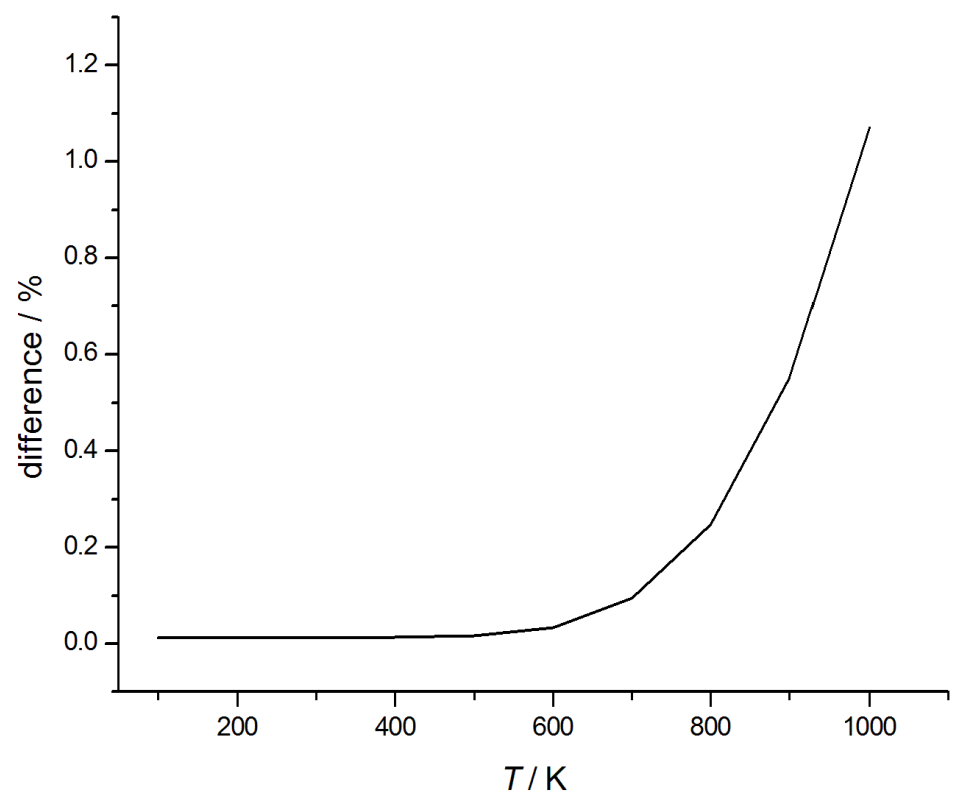

Figure 3. Comparison of the present $Q_{\text {int }}(T)$ values of $\mathrm{D}_{2}{ }^{16} \mathrm{O}$ with those of Hewitt et al., defined with respect to the present values.

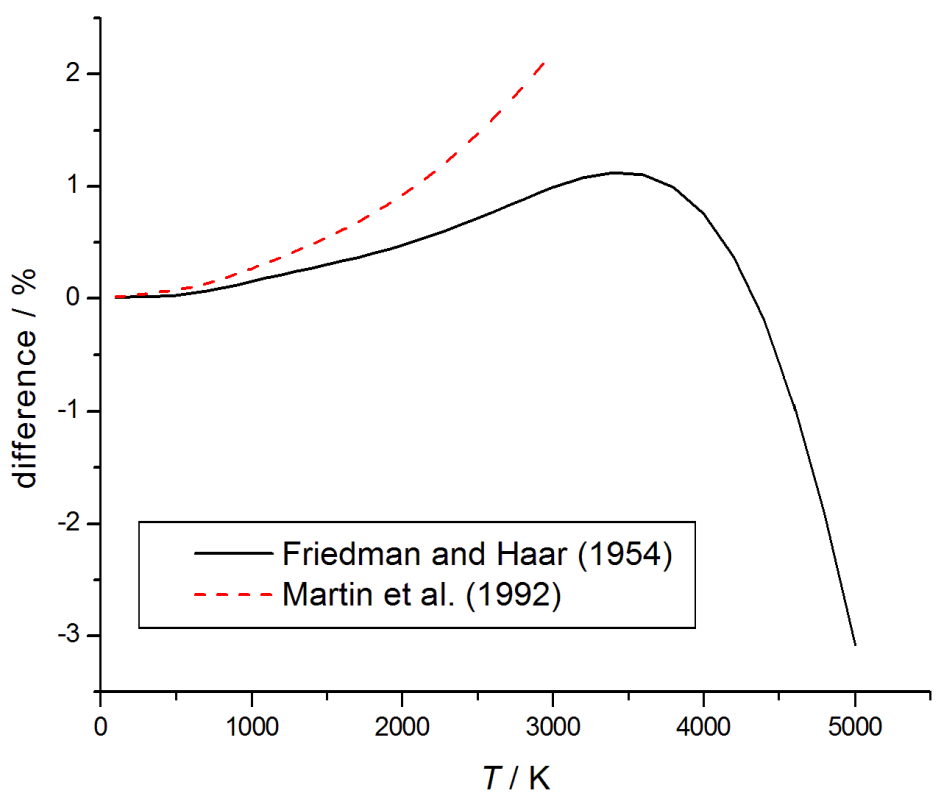

Figure 4. Comparison of the present $C_{p}(T)$ values of $\mathrm{D}_{2}{ }^{16} \mathrm{O}$ with those of Friedman and Haar $(\mathrm{FH})$ (full, black curve) and Martin et al. (dashed, red curve). 
Table 3. The temperature-dependent nuclear-spin-equilibrated internal partition functions, $Q_{\text {int }}(T)$, of $\mathrm{D}_{2}{ }^{16} \mathrm{O}$ and its first two moments, $Q_{\mathrm{int}}^{\prime}(T)$ and $Q_{\mathrm{int}}^{\prime \prime}(T)$. The standard uncertainties associated with the data are given in parentheses.

\begin{tabular}{|c|c|c|c|c|c|c|}
\hline$T / \mathrm{K}$ & $Q_{\mathrm{int}}(T)$ & $Q_{\text {int }}^{\prime}(T)$ & $Q_{\text {int }}^{\prime \prime}(T)$ & $T / \mathrm{K} Q_{\text {int }}(T)$ & $Q_{\mathrm{int}}^{\prime}(T)$ & $Q_{\text {int }}^{\prime \prime}(T)$ \\
\hline 100 & $203.437(3)$ & $300.805(2)$ & $750.952(3)$ & $3100170810(60)$ & $574970(370)$ & $2708380(2904)$ \\
\hline 200 & $570.081(4)$ & $851.998(3)$ & $2141.878(8)$ & $3200190187(74)$ & 647162(461) & $3067770(3715)$ \\
\hline 298.15 & $1039.136(6)$ & $1577.002(6)$ & $4077.37(2)$ & $3300211295(89)$ & $726423(574)$ & $3464231(4741)$ \\
\hline 300 & $1048.939(6)$ & $1592.554(7)$ & $4120.61(2)$ & $3400234252(109)$ & $813262(715)$ & $3900491(6032)$ \\
\hline 400 & $1632.887(9)$ & $2554.16(2)$ & $6912.96(7)$ & $3500259175(132)$ & 908205(889) & $4379374(7647)$ \\
\hline 500 & $2330.08(1)$ & $3791.40(4)$ & $10767.8(2)$ & $3600286191(160)$ & 1011801(1103) & $4903787(9653)$ \\
\hline 600 & $3154.99(2)$ & $5367.78(8)$ & $15988.2(4)$ & $3700315431(193)$ & $1124619(1366)$ & $5476720(12134)$ \\
\hline 700 & $4126.10(4)$ & $7358.7(2)$ & $22943.2(9)$ & $3800347028(234)$ & $1247249(1686)$ & $6101225(15190)$ \\
\hline 800 & $5265.34(7)$ & $9851.2(3)$ & $32050(2)$ & $3900381123(282)$ & $1380297(2076)$ & 6780394(18940) \\
\hline 900 & $6597.7(1)$ & $12942.2(5)$ & $43765(3)$ & $4000417861(340)$ & $1524388(2548)$ & 7517394(23540) \\
\hline 1000 & $8151.1(2)$ & $16737.7(8)$ & $58592(5)$ & $4100457393(410)$ & $1680163(3118)$ & 8315392(29181) \\
\hline 1100 & $9955.8(3)$ & 21353(1) & $77081(8)$ & $4200499873(492)$ & $1848279(3807)$ & 9177646(36129) \\
\hline 1200 & $12044.8(4)$ & $26913(2)$ & $99842(12)$ & $4300545460(590)$ & 2029406(4636) & 10107338(44691) \\
\hline 1300 & $14453.6(6)$ & $33555(3)$ & $127546(18)$ & $4400594319(707)$ & $2224225(5635)$ & 11107654(55249) \\
\hline 1400 & $17220.3(9)$ & $41425(4)$ & $160929(27)$ & $4500646618(844)$ & $2433433(6840)$ & 12181919(68358) \\
\hline 1500 & $20386(1)$ & $50682(6)$ & $200799(38)$ & $4600702530(1007)$ & $2657730(8297)$ & $13333573(84793)$ \\
\hline 1600 & 23993(2) & $61500(9)$ & $248035(53)$ & $4700762231(1199)$ & 2897832(10060) & 14564939(104759) \\
\hline 1700 & $28089(2)$ & $74063(12)$ & $303596(73)$ & $4800825903(1426)$ & 3154458(12199) & 15880826(130245) \\
\hline 1800 & $32723(3)$ & $88573(16)$ & $368521(99)$ & $4900893729(1694)$ & $3428334(14800)$ & 17283265(161579) \\
\hline 1900 & $37949(4)$ & $105243(21)$ & 443931(133) & $5000965898(2012)$ & 3720196(17963) & 18775197(199802) \\
\hline 2000 & $43821(5)$ & $124304(28)$ & $531041(177)$ & $51001042601(2389)$ & $4030781(21812)$ & $20360698(247075)$ \\
\hline 2100 & $50399(7)$ & $146001(36)$ & $631154(232)$ & $52001124033(2837)$ & 4360834(26491) & 22043310(305414) \\
\hline 2200 & $57747(9)$ & 170599(47) & 745671(303) & $53001210392(3370)$ & 4711104(32170) & 23825486(376108) \\
\hline 2300 & $65931(11)$ & 198377(60) & 876096(393) & $54001301878(4004)$ & $5082344(39045)$ & 25707939(459020) \\
\hline 2400 & $75021(14)$ & $229634(76)$ & 1024034(507) & $55001398695(4759)$ & $5475316(47340)$ & $27701470(563336)$ \\
\hline 2500 & $85093(18)$ & $264686(96)$ & 1191201(653) & $56001501050(5658)$ & $5890781(57310)$ & $29802534(685556)$ \\
\hline 2600 & $96223(22)$ & $303870(121)$ & 1379423(838) & $57001609150(6728)$ & $6329509(69241)$ & $32012311(826479)$ \\
\hline 2700 & $108496(27)$ & $347543(152)$ & $1590642(1075)$ & $58001723208(8000)$ & $6792280(83458)$ & $34344308(998803)$ \\
\hline 2800 & 121997(33) & 396081(190) & 1826915(1379) & $59001843438(9509)$ & $7279882(100322)$ & $36796103(1200524)$ \\
\hline 2900 & $136818(41)$ & $449881(237)$ & 2090415(1768) & $60001970056(11294)$ & 7793107(120231) & $39363667(1428102)$ \\
\hline 3000 & $153056(50)$ & $509364(296)$ & $2383435(2267)$ & & & \\
\hline
\end{tabular}

Figure 4 compares our values of $\mathrm{D}_{2}{ }^{16} \mathrm{O} C_{p}(T)$ with data from Friedman and Haar $(\mathrm{FH})^{15}$ and Martin et al. ${ }^{23}$ The figure suggests that the results of $\mathrm{FH}$ are reasonable for temperatures up to about $4000 \mathrm{~K}$, while those of Martin et al. systematically underestimate the heat capacity starting at the lowest temperatures.

\subsection{Isotopic composition of heavy water}

As mentioned above, IAPWS ${ }^{7}$ defines "heavy water" 8 as a mixture of water isotopologues whose hydrogen content is pure ${ }^{2} \mathrm{H}(\mathrm{D})$ and whose oxygen content has the isotopic composition of VSMOW. ${ }^{9-11}$ The convention of using VSMOW's oxygen composition for heavy 
Table 4. The temperature-dependent nuclear-spin-equilibrated internal partition functions, $Q_{\text {int }}(T)$, of $\mathrm{D}_{2}{ }^{17} \mathrm{O}$ and its first two moments, $Q_{\mathrm{int}}^{\prime}(T)$ and $Q_{\mathrm{int}}^{\prime \prime}(T)$. The standard uncertainties associated with the data are given in parentheses.

\begin{tabular}{|c|c|c|c|c|c|c|}
\hline$T / \mathrm{K}$ & $Q_{\text {int }}(T)$ & $Q_{\text {int }}^{\prime}(T)$ & $Q_{\text {int }}^{\prime \prime}(T)$ & $T / \mathrm{K} Q_{\text {int }}(T)$ & $Q_{\text {int }}^{\prime}(T)$ & $Q_{\text {int }}^{\prime \prime}(T)$ \\
\hline 100 & $1230.2(2)$ & 1819.1(1) & $4541.4(3)$ & $31001037626(712)$ & $3496406(3347)$ & $16484328(25596)$ \\
\hline 200 & $3447.5(5)$ & $5153(1)$ & $12955(8)$ & $32001155463(830)$ & 3935931(4151) & $18674383(32848)$ \\
\hline 298.15 & $6285(2)$ & $9540(6)$ & $24677(25)$ & $33001283851(973)$ & $4418568(5154)$ & $21090618(42036)$ \\
\hline 300 & $6344(2)$ & $9634(6)$ & $24939(25)$ & $34001423494(1144)$ & $4947410(6402)$ & $23749686(53590)$ \\
\hline 400 & $9877(5)$ & $15458(13)$ & $41867(45)$ & $35001575125(1351)$ & $5525680(7947)$ & $26668804(68010)$ \\
\hline 500 & $14098(9)$ & $22957(22)$ & $65252(65)$ & $36001739507(1601)$ & $6156727(9852)$ & $29865707(85865)$ \\
\hline 600 & 19094(13) & $32516(31)$ & $96933(89)$ & $37001917435(1901)$ & $6844024(12188)$ & $33358608(107813)$ \\
\hline 700 & & $44594(4$ & 139150(117) & $38002109734(2263)$ & 7591163(15037) & 37166104 \\
\hline 800 & $31883(25)$ & $59719(53)$ & 194430(150) & $39002317260(2696)$ & $8401850(18493)$ & 41307025(167109) \\
\hline 900 & $39961(32)$ & $78477(66)$ & $265547(19$ & $40002540898(321$ & $9279894(22660)$ & $45800643(20$ \\
\hline 1000 & $49381(40)$ & 101513(80) & $355547(237)$ & $41002781565(3831)$ & $10229205(27663)$ & $50666215(253548)$ \\
\hline 1100 & $60328(48)$ & $129527(97)$ & $467786(291)$ & $42003040204(4564)$ & 11253781(33639) & $55923535(310234)$ \\
\hline 1200 & & $163279(116)$ & & $43003317788(5432)$ & & $61591943(378180)$ \\
\hline 1300 & $87615(67)$ & 203596(137) & $774182(426)$ & $44003615319(6456)$ & $13545139(49188)$ & $67690767(459525)$ \\
\hline 1400 & 104403(78) & $251372(160)$ & $976911(5$ & $45003933823(76$ & 14820301 & 74240165 \\
\hline 1500 & $123611(90)$ & $307580(187)$ & $1219075(6$ & $46004274354(9070)$ & $16187475(70979)$ & $81260967(675428)$ \\
\hline 1600 & $145505(103)$ & $373268(218)$ & $1506041(742)$ & $47004637989(10719)$ & $17650997(84921)$ & 88767272( \\
\hline 1700 & 170367 & $449568(253)$ & $1843652(90$ & $48005025831(12643)$ & $19215245(101390)$ & $96788084(988250)$ \\
\hline 1800 & $198499(133)$ & $537699(295)$ & $2238245(1106)$ & $49005439003(14884)$ & $20884640(120855)$ & 105335722 \\
\hline 1900 & $230222(150)$ & $638970(344)$ & 2696674(1371) & $50005878650(17490)$ & $22663631(143882)$ & 114427930( \\
\hline 2000 & $265876(169)$ & $754784(403)$ & $3226339(1714)$ & $51006345940(20520)$ & $24556708(171151)$ & $124089255(1745489)$ \\
\hline 2100 & $305824(191)$ & $886643(476)$ & $3835206(2159)$ & $52006842057(24040)$ & $26568381(203474)$ & 134341002(2111689) \\
\hline 2200 & $350450(215)$ & $1036151(565)$ & $4531832(2736)$ & $53007368205(28132)$ & $28703191(241808)$ & $145197936(2550942)$ \\
\hline 2300 & $400159(242)$ & $1205020(675)$ & $5325392(3481)$ & $54007925606(32887)$ & $30965699(287273)$ & $156664345(3063762)$ \\
\hline 2400 & $455381(274)$ & $1395070(811)$ & $6225699(4443)$ & $55008515498(38418)$ & $33360512(341177)$ & 168805034(3701178) \\
\hline 2500 & $516570(310)$ & $1608237(980)$ & $7243230(5684)$ & $56009139135(44854)$ & $35892240(405007)$ & $181598712(4446031)$ \\
\hline 2600 & $584204(353)$ & $1846574(1191)$ & $8389143(7286)$ & $57009797788(52346)$ & $38565538(480459)$ & $195052408(5303640)$ \\
\hline 2700 & $658787(402)$ & $2112258(1453)$ & $9675296(9354)$ & $580010492742(61070)$ & $41385109(569458)$ & 209247097(6346469) \\
\hline 2800 & $740849(461)$ & $2407588(1781)$ & $11114255(12025)$ & $590011225296(71227)$ & $44355710(674170)$ & $224168167(7565024)$ \\
\hline 2900 & $830948(530)$ & $2734994(2191)$ & 12719301(15472) & $600011996765(83048)$ & $47482113(796975)$ & 239791330(8939948) \\
\hline 3000 & $929669(613)$ & $3097036(2705)$ & $14504428(19909)$ & & & \\
\hline
\end{tabular}

water can be traced back to the work of Kell. ${ }^{52}$ An analysis ${ }^{53}$ of these batches provided an isotopic abundance of $a_{18}=N\left({ }^{18} \mathrm{O}\right) / N\left({ }^{16} \mathrm{O}\right)=2005.20 \times 10^{-6}$ with a standard uncertainty of $u_{18}=0.45 \times 10^{-6}$. Later, the isotopic abundance $a_{17}=N\left({ }^{17} \mathrm{O}\right) / N\left({ }^{16} \mathrm{O}\right)$ was determined ${ }^{54}$ as $379.9 \times 10^{-6}$ with a standard uncertainty of $u_{17}=0.8 \times 10^{-6}$. These isotopic abundances have been cited in a NIST report ${ }^{10}$ and, recently, re-affirmed ${ }^{11}$ for the new VSMOW2 definition. The corresponding values ${ }^{8}$ of molar fractions, $x$, of the individual isotopologues are as follows: $0.9976206,0.0003790$, and 0.0020004 for $\mathrm{D}_{2}{ }^{16} \mathrm{O}, \mathrm{D}_{2}{ }^{17} \mathrm{O}$, and $\mathrm{D}_{2}{ }^{18} \mathrm{O}$, respectively. These molar fractions are obtained as

$$
x_{16}=\frac{1}{1+a_{17}+a_{18}}, \quad x_{17}=\frac{a_{17}}{1+a_{17}+a_{18}}, \quad x_{18}=\frac{a_{18}}{1+a_{17}+a_{18}} .
$$


Table 5. The temperature-dependent nuclear-spin-equilibrated internal partition functions, $Q_{\text {int }}(T)$, of $\mathrm{D}_{2}{ }^{18} \mathrm{O}$ and their first two moments, $Q_{\text {int }}^{\prime}(T)$ and $Q_{\text {int }}^{\prime \prime}(T)$. The standard uncertainties associated with the data are given in parentheses.

\begin{tabular}{|c|c|c|c|c|c|}
\hline$T / \mathrm{K} \quad Q_{\text {int }}(T)$ & $Q_{\text {int }}^{\prime}(T)$ & $Q_{\text {int }}^{\prime \prime}(T)$ & $T / \mathrm{K} Q_{\text {int }}(T)$ & $Q_{\text {int }}^{\prime}(T)$ & $Q_{\text {int }}^{\prime \prime}(T)$ \\
\hline $100206.475(9)$ & $305.334(5)$ & $762.277(8)$ & $3100175096(102)$ & $590562(557)$ & $2785888(4329)$ \\
\hline $200578.65(1)$ & $864.917(8)$ & $2174.80(2)$ & $3200195000(122)$ & $664857(693)$ & $3156266(5556)$ \\
\hline $298.151054 .92(2)$ & $1601.70(2)$ & $4144.60(6)$ & $3300216688(146)$ & $746446(863)$ & $3564921(7108)$ \\
\hline $3001064.88(2)$ & $1617.51(2)$ & $4188.66(6)$ & $3400240280(175)$ & $835852(1074)$ & $4014670(9060)$ \\
\hline $4001658.22(3)$ & $2596.31(5)$ & $7036.1(3)$ & $3500265898(209)$ & $933621(1336)$ & 4508425(11495) \\
\hline $5002367.24(5)$ & $3857.4(2)$ & 10972(1) & $3600293673(251)$ & $1040319(1658)$ & $5049187(14508)$ \\
\hline $6003206.9(1)$ & $5465.9(5)$ & $16308(3)$ & $3700323739(302)$ & $1156535(2053)$ & $5640032(18211)$ \\
\hline $7004196.2(2)$ & 7499(1) & $23422(6)$ & $3800356236(363)$ & $1282876(2534)$ & $6284105(22729)$ \\
\hline $8005357.6(4)$ & $10047(2)$ & $32740(10)$ & $3900391308(436)$ & $1419969(3118)$ & $6984584(28206)$ \\
\hline $9006716.9(7)$ & $13207(3)$ & $44732(15)$ & $4000429106(523)$ & $1568458(3821)$ & $7744722(34817)$ \\
\hline $10008303(1)$ & $17090(5)$ & $59911(23)$ & $4100469784(627)$ & $1729005(4665)$ & $8567769(42760)$ \\
\hline $110010146(2)$ & $21813(7)$ & $78846(32)$ & $4200513502(751)$ & $1902285(5673)$ & $9457061(52293)$ \\
\hline $120012280(2)$ & $27504(9)$ & 102162(42) & $4300560424(897)$ & $2088988(6872)$ & 10415857(63712) \\
\hline $130014742(3)$ & $34304(12)$ & $130549(55)$ & $4400610721(1070)$ & 2289816(8293) & 11447412(77369) \\
\hline $140017571(4)$ & $42364(16)$ & $164768(70)$ & $4500664566(1273)$ & $2505483(9974)$ & 12555115(93761) \\
\hline $150020809(5)$ & $51847(20)$ & $205648(89)$ & $4600722136(1511)$ & 2736712(11960) & $13742468(113565)$ \\
\hline $160024500(7)$ & $62932(25)$ & 254099(111) & $4700783614(1789)$ & 2984233(14303) & 15011844(137061) \\
\hline $170028692(9)$ & $75809(31)$ & 311109(139) & $4800849187(2113)$ & 3248786(17069) & 16368099(165915) \\
\hline $180033436(10)$ & $90685(38)$ & $377749(175)$ & $4900919044(2491)$ & $3531114(20336)$ & 17813305(200580) \\
\hline $190038786(13)$ & 107782(46) & $455179(220)$ & $5000993379(2929)$ & $3831969(24197)$ & 19350434(242078) \\
\hline $200044801(15)$ & $127335(56)$ & $544652(280)$ & $51001072389(3439)$ & $4152104(28765)$ & 20983590(292399) \\
\hline $210051541(18)$ & 149601(69) & $647516(356)$ & $52001156274(4031)$ & $4492281(34176)$ & 22716331(353503) \\
\hline $220059071(22)$ & $174849(84)$ & $765220(455)$ & $53001245238(4718)$ & 4853262(40589) & 24551123(426773) \\
\hline $230067460(26)$ & 203371(103) & $899316(582)$ & $54001339485(5517)$ & $5235814(48189)$ & $26488683(512300)$ \\
\hline $240076780(31)$ & $235472(126)$ & $1051466(746)$ & $55001439227(6445)$ & $5640710(57195)$ & 28539810(618571) \\
\hline $250087109(37)$ & $271482(155)$ & $1223444(957)$ & $56001544673(7524)$ & $6068724(67854)$ & $30700950(742742)$ \\
\hline $260098527(43)$ & 311749(191) & 1417141(1229) & $57001656038(8780)$ & $6520638(80448)$ & 32973266(885705) \\
\hline $2700111119(51)$ & $356639(235)$ & $1634564(1580)$ & $58001773540(10241)$ & 6997238(95298) & $35370243(1059518)$ \\
\hline $2800124975(61)$ & $406543(291)$ & $1877841(2033)$ & $59001897396(11940)$ & 7499323(112766) & $37889432(1262613)$ \\
\hline $2900140190(72)$ & $461872(361)$ & $2149221(2616)$ & $60002027828(13917)$ & $8027690(133247)$ & $40526766(1491771)$ \\
\hline $3000156862(86)$ & $523060(448)$ & $2451074(3367)$ & & & \\
\hline
\end{tabular}

The properties of heavy water in the ideal gas state are obtained as properties of a mixture of ideal gas components. The components are the individual isotopologues $\mathrm{D}_{2}{ }^{16} \mathrm{O}, \mathrm{D}_{2}{ }^{17} \mathrm{O}$, and $\mathrm{D}_{2}{ }^{18} \mathrm{O}$, for which, as usual in thermochemistry, we assume nuclear-spin equilibration. Of particular importance for this study is the isobaric heat capacity, which can be obtained as

$$
C_{p}=x_{16} C_{p, 16}+x_{17} C_{p, 17}+x_{18} C_{p, 18} .
$$

The uncertainties of the isotopic abundances result in a contribution to the uncertainty of the thermodynamic properties of heavy water. The abundances $a_{17}$ and $a_{18}$ have been determined independently and, therefore, can be assumed to be uncorrelated. However, the 
Table 6. Thermochemical functions of $\mathrm{D}_{2}{ }^{16} \mathrm{O}, \mathrm{D}_{2}{ }^{17} \mathrm{O}$, and $\mathrm{D}_{2}{ }^{18} \mathrm{O}$; the standard uncertainties associated with the data are given in parentheses.

\begin{tabular}{|c|c|c|c|c|c|c|c|c|c|}
\hline \multirow[t]{3}{*}{$T / \mathrm{K}$} & \multicolumn{3}{|c|}{$C_{p}(T) / \mathrm{J} \mathrm{K}^{-1} \mathrm{~mol}^{-1}$} & \multicolumn{3}{|c|}{$S(T) / \mathrm{J} \mathrm{K}^{-1} \mathrm{~mol}^{-1}$} & \multicolumn{3}{|c|}{$\bar{~} H(T) / \mathrm{kJ} \mathrm{mol}^{-1}$} \\
\hline & $\mathrm{D}_{2}{ }^{16} \mathrm{O}$ & $\mathrm{D}_{2}{ }^{17} \mathrm{O}$ & $\mathrm{D}_{2}{ }^{18} \mathrm{O}$ & $\mathrm{D}_{2}{ }^{16} \mathrm{O}$ & $\mathrm{D}_{2}{ }^{17} \mathrm{O}$ & $\mathrm{D}_{2}{ }^{18} \mathrm{O}$ & $\mathrm{D}_{2}{ }^{16} \mathrm{O}$ & $\mathrm{D}_{2}{ }^{17} \mathrm{O}$ & $\mathrm{D}_{2}{ }^{18} \mathrm{O}$ \\
\hline & $33.299595(9)$ & $33.2996(3)$ & $33.29960(7)$ & $180.01202(2)$ & $195.5856(2)$ & $181.32654(3)$ & $3.308004(9)$ & $3.3081(1)$ & $3.30815(3)$ \\
\hline 200 & $33.45369(1)$ & $33.457(9)$ & 33.45934(1) & $203.11953(2)$ & $218.694(3)$ & $204.43493(2)$ & $6.642458(8)$ & $6.6426(3)$ & $6.64276(4)$ \\
\hline 98.15 & $34.26113(4)$ & $34.27(1)$ & $34.2851(2)$ & $216.60269(3)$ & $232.180(7)$ & $217.92364(5)$ & $9.959477(6)$ & $9.960(1)$ & $9.96121(3)$ \\
\hline 300 & $34.28280(4)$ & $34.30(1)$ & $34.3072(2)$ & $216.81469(3)$ & $232.392(7)$ & $218.13578(5)$ & $10.022880(6)$ & 10.024(1) & $10.02465(3)$ \\
\hline 400 & $35.6429(1)$ & $35.664(5)$ & $35.6830(9)$ & $226.85627(5)$ & $242.439(9)$ & $228.1867(2)$ & $13.516657(2)$ & $13.519(2)$ & $13.52171(2)$ \\
\hline 500 & $37.1955(3)$ & $37.22210(2)$ & $37.247(2)$ & $234.9742(1)$ & $250.56(1)$ & $236.3149(5)$ & $17.15754(2)$ & $17.163(2)$ & $17.1672(2)$ \\
\hline 600 & $38.8531(5)$ & $38.883(3)$ & $38.914(3)$ & $241.9010(2)$ & $257.494(9)$ & $243.252(1)$ & 20.95924(6) & $20.967(2)$ & $20.9745(5)$ \\
\hline 700 & $40.5727(7)$ & $40.603(5)$ & $40.639(5)$ & $248.0189(3)$ & $263.616(9)$ & $249.380(2)$ & $24.9303(1)$ & $24.941(2)$ & $24.9519(9)$ \\
\hline 800 & $42.2909(9)$ & $42.320(6)$ & $42.358(5)$ & 253.5492(4) & 269.151(8) & $254.919(2)$ & $29.0737(2)$ & $29.088(1)$ & $29.102(1)$ \\
\hline 900 & $43.946(1)$ & $43.971(7)$ & $44.011(5)$ & $258.6267(5)$ & $274.231(7)$ & $260.004(3)$ & $33.3863(3)$ & $33.4030(5)$ & $33.421(2)$ \\
\hline 1000 & $45.494(2)$ & $45.514(7)$ & $45.555(5)$ & 263.3381(7) & $278.945(6)$ & $264.722(3)$ & $37.8593(5)$ & $37.8783(2)$ & $37.901(2)$ \\
\hline 1100 & $46.912(2)$ & $46.929(8)$ & $46.969(4)$ & $267.7417(8)$ & $283.351(6)$ & $269.132(4)$ & $42.4807(7)$ & $42.5015(9)$ & $42.528(3)$ \\
\hline 1200 & $48.195(3)$ & $48.208(8)$ & $48.248(4)$ & $271.880(1)$ & $287.490(5)$ & $273.274(4)$ & $47.2371(9)$ & $47.260(2)$ & $47.290(3)$ \\
\hline 1300 & $49.345(3)$ & $49.358(7)$ & $49.395(3)$ & $275.783(1)$ & $291.395(5)$ & $277.182(5)$ & $52.115(1)$ & $52.139(2)$ & $52.173(4)$ \\
\hline 1400 & $50.373(4)$ & $50.386(7)$ & $50.422(2)$ & $279.479(2)$ & 295.091(4) & $280.881(5)$ & $57.102(2)$ & $57.127(3)$ & $57.165(4)$ \\
\hline 1500 & $51.291(4)$ & $51.305(6)$ & $51.339(1)$ & $282.986(2)$ & $298.599(4)$ & $284.392(5)$ & $62.186(2)$ & $62.212(4)$ & $62.254(4)$ \\
\hline 1600 & $52.112(5)$ & $52.128(5)$ & $52.1598(7)$ & $286.323(2)$ & $301.937(3)$ & $287.732(5)$ & $67.357(2)$ & $67.385(4)$ & $67.430(4)$ \\
\hline 1700 & $52.846(5)$ & $52.866(3)$ & $52.8959(8)$ & $289.505(2)$ & $305.120(3)$ & $290.916(5)$ & $72.606(3)$ & $72.635(5)$ & $72.683(4)$ \\
\hline 1800 & $53.507(6)$ & $53.529(2)$ & $53.558(1)$ & $292.544(3)$ & $308.161(3)$ & $293.959(5)$ & $77.924(3)$ & $77.955(5)$ & $78.006(4)$ \\
\hline 1900 & $54.102(7)$ & $54.1291(6)$ & $54.156(2)$ & $295.453(3)$ & $311.071(3)$ & $296.871(5)$ & $83.305(4)$ & $83.339(5)$ & $83.393(4)$ \\
\hline 2000 & $54.642(8)$ & $54.673(3)$ & $54.699(4)$ & $298.242(3)$ & $313.862(3)$ & $299.663(5)$ & $88.743(5)$ & $88.779(5)$ & $88.836(5)$ \\
\hline 2100 & $55.134(9)$ & $55.169(6)$ & $55.194(6)$ & $300.921(4)$ & $316.541(3)$ & $302.344(5)$ & $94.232(6)$ & $94.272(4)$ & $94.331(5)$ \\
\hline 2200 & $55.58(1)$ & $55.622(9)$ & $55.646(8)$ & $303.496(4)$ & $319.118(3)$ & $304.922(6)$ & $99.768(6)$ & $99.812(4)$ & $99.873(6)$ \\
\hline 2300 & $56.00(1)$ & $56.04(1)$ & $56.06(1)$ & $305.976(5)$ & $321.600(4)$ & $307.405(6)$ & $105.347(8)$ & $105.395(3)$ & $105.459(7)$ \\
\hline 2400 & $56.38(1)$ & $56.42(2)$ & $56.45(1)$ & $308.367(5)$ & $323.993(4)$ & $309.799(7)$ & $110.966(9)$ & $111.018(1)$ & $111.084(8)$ \\
\hline 2500 & $56.73(1)$ & $56.78(2)$ & $56.80(2)$ & $310.676(6)$ & $326.304(5)$ & $312.111(7)$ & 116.62(1) & $116.6789(6)$ & $116.75(1)^{\prime}$ \\
\hline 2600 & $57.06(2)$ & $57.11(2)$ & $57.14(2)$ & $312.908(6)$ & $328.538(6)$ & $314.345(8)$ & 122.31(1) & $122.374(3)$ & $122.44(1)$ \\
\hline 2700 & $57.37(2)$ & $57.42(3)$ & 57.44 & $315.067(7)$ & $330.699(7)$ & $316.507(9)$ & $128.03(1)$ & $128.101(6)$ & $128.17(1)$ \\
\hline 2800 & $57.66(2)$ & $57.71(4)$ & $57.73(3)$ & $317.159(8)$ & $332.792(8)$ & $318.60(1)^{\prime}$ & $133.78(2)$ & $133.857(9)$ & $133.93(2)$ \\
\hline 2900 & $57.92(3)$ & $57.98(4)$ & $58.00(4)$ & $319.186(9)$ & $334.82(1)$ & $320.63(1)$ & $139.56(2)$ & 139.64(1) & $139.72(2)$ \\
\hline 3000 & $58.18(3)$ & $58.23(5)$ & $58.26(5)$ & $321.15(1)$ & $336.79(1)$ & 322.6 & $7(2)$ & $145.45(2)$ & $145.53(3)$ \\
\hline 3100 & $58.41(4)$ & $58.47(6)$ & 58.49 & & 338.71(1) & 324.5 & (3) & $151.29(2)$ & $151.37(3)$ \\
\hline 3200 & $58.63(5)$ & $58.69(8)$ & $58.71(7)$ & $324.92(1)$ & $340.57(2)$ & $326.38(2)$ & $157.05(3)$ & $157.15(3)$ & $157.23(4)$ \\
\hline 3300 & $58.83(6)$ & $58.89(9)$ & $58.91(9)$ & $326.73(1)$ & $342.37(2)$ & $328.19(2)$ & $162.92(3)$ & $163.03(4)$ & $163.11(5)$ \\
\hline 3400 & $59.01(7)$ & $59.1(1)$ & $59.1(1)$ & 328.4 & $344.14(2)$ & 329.9 & 2(4) & $168.92(5)$ & $169.01(5)$ \\
\hline 3500 & $59.18(8)$ & $59.2(1)$ & $59.3(1)$ & $330.20(2)$ & $345.85(2)$ & $331.66(3)$ & $174.73(5)$ & $174.84(6)$ & $174.93(7)$ \\
\hline 3600 & $59.33(9)$ & $59.4(1)$ & $59.4(1)$ & $331.87(2)$ & $347.52(3)$ & $333.34(3)$ & $180.65(6)$ & $180.77(7)$ & $180.86(8)$ \\
\hline 3700 & $59.5(1)$ & $.5(2)$ & 2) & $0(2)$ & $9.15(3)$ & (3) & $59(7)$ & 186.71(9) & $186.81(9)$ \\
\hline 3800 & 59.6(1) & $59.6(2)$ & $59.6(2)$ & $335.09(3)$ & $350.74(4)$ & $336.55(4)$ & $192.54(8)$ & $192.7(1)$ & $192.8(1)$ \\
\hline 3900 & $59.6(1)$ & $59.7(2)$ & $59.7(2)$ & $336.64(3)$ & $352.29(4)$ & $338.10(4)$ & $198.50(9)$ & 198.6(1) & 198.7(1) \\
\hline & $7(2)$ & $8(2)$ & 2) & & $3.80(5)$ & & & & $7(1)$ \\
\hline 4100 & $59.8(2)$ & $8(3)$ & $59.8(3)$ & $9.62(4)$ & $355.28(5)$ & $341.09(5)$ & 210.4(1) & $210.6(2)$ & $210.7(2)$ \\
\hline 4200 & $59.8(2)$ & $9.8(3)$ & $59.8(3)$ & 41.06(4) & $356.72(6)$ & $342.53(6)$ & 216.4(1) & $216.6(2)$ & $216.7(2)$ \\
\hline & $8(3)$ & & & & $3.12(7)$ & & & $222.5(2)$ & $222.6(2)$ \\
\hline 4400 & $59.7(3)$ & $8(4)$ & $9.8(4)$ & $3.84(5)$ & $359.50(7)$ & $345.31(7)$ & $228.4(2)$ & $228.5(3)$ & $228.6(3)$ \\
\hline 4500 & $59.7(4)$ & $59.7(4)$ & $59.7(4)$ & $345.18(6)$ & $360.84(8)$ & $346.66(8)$ & $234.3(2)$ & $234.5(3)$ & $234.6(3)$ \\
\hline & $6(4)$ & & & & $362.15(9)$ & & & $240.5(3)$ & $240.6(3)$ \\
\hline 4700 & $5(5)$ & $5(5)$ & $5(5)$ & $7.77(7)$ & $363.4(1)$ & 349.2 & $246.3(3)$ & $246.4(4)$ & $246.5(4)$ \\
\hline 4800 & $59.4(6)$ & $59.4(6)$ & $59.4(6)$ & 349.03(8) & $364.7(1)$ & $350.5(1)$ & $252.2(3)$ & $252.4(4)$ & $252.5(4)$ \\
\hline & $59.2(7)$ & & & & & & & $258.3(5)$ & $258.4(5)$ \\
\hline 5000 & $1(8)$ & $1(8)$ & $59.0(8)$ & $.4(1)$ & $367.1(1)$ & $352.9(1)$ & $264.0(5)$ & $264.2(6)$ & $264.3(6)$ \\
\hline 5100 & $58.9(9)$ & $58.9(9)$ & $58.8(9)$ & $352.6(1)$ & $368.3(2)$ & $354.1(2)$ & $269.9(5)$ & $270.1(6)$ & $270.2(6)$ \\
\hline 5200 & $59(1)^{\prime}$ & $59(1)$ & & & $369.4(2)$ & $355.2(2)$ & $275.8(6)$ & $276.0(7)$ & $276.1(7)$ \\
\hline 5300 & & & & & & & $281.7(7)$ & $281.8(8)$ & $281.9(8)$ \\
\hline 5400 & $58(1)$ & $58(1)$ & $58(1)$ & $356.0(2)$ & $371.6(2)$ & $357.4(2)$ & $287.5(8)$ & $288(1)$ & $287.7(9)$ \\
\hline 5500 & $58(2)$ & $58(2)$ & $58(2)$ & $357.0(2)$ & $372.7(2)$ & $358.5(2)$ & 293(1) & 293(1) & 294(1) \\
\hline 5600 & $58(2)$ & $58(2)$ & & & $373.7(3)$ & & & & 299(1) \\
\hline 5700 & $58(2)$ & $57(2)$ & $57(2)$ & $359.1(3)$ & $374.7(3)$ & $360.6(3)$ & $305(1)$ & $305(1)$ & $305(1)$ \\
\hline 5800 & $57(2)$ & $57(2)$ & $57(2)$ & $360.1(3)$ & $375.7(3)$ & $361.6(3)$ & $311(2)$ & $311(2)$ & $311(2)$ \\
\hline 5900 & $57(2)$ & $57(2)$ & $57(2)$ & $361.1(3)$ & $376.7(4)$ & & & $316(2)$ & $317(2)$ \\
\hline 6000 & $57(3)$ & $57(3)$ & $57(3)$ & $362.0(4)$ & $377.7(4)$ & $363.5(4)$ & $322(2)$ & $322(2)$ & $322(2)$ \\
\hline
\end{tabular}


Table 7. The $Q_{\text {int }}(T)$ partition function and the $C_{p}(T)$ isobaric heat capacity of heavy water determined in this study.

\begin{tabular}{cll}
\hline \hline$T / \mathrm{K}$ & \multicolumn{1}{c}{$Q_{\text {int }}(T)$} & \multicolumn{1}{c}{$C_{p}(T) / \mathrm{J} \mathrm{K} \mathrm{mol}^{-1}$} \\
\hline 100 & $203.832(5)$ & $33.29960(1)$ \\
200 & $571.19(1)$ & $33.4537(2)$ \\
298.15 & $1041.16(4)$ & $34.2612(2)$ \\
300 & $1050.98(4)$ & $34.2829(2)$ \\
400 & $1636.06(9)$ & $35.6430(2)$ \\
500 & $2334.6(2)$ & $37.1956(3)$ \\
600 & $3161.1(3)$ & $38.8532(5)$ \\
700 & $4134.1(4)$ & $40.5728(7)$ \\
800 & $5275.6(5)$ & $42.291(1)$ \\
900 & $6610.6(6)$ & $43.946(1)$ \\
1000 & $8167.0(8)$ & $45.494(2)$ \\
1100 & $9975(1)$ & $46.912(2)$ \\
1200 & $12068(1)$ & $48.195(3)$ \\
1300 & $14482(1)$ & $49.345(3)$ \\
1400 & $17254(2)$ & $50.374(4)$ \\
1500 & $20425(2)$ & $51.292(4)$ \\
1600 & $24040(3)$ & $52.112(5)$ \\
1700 & $28144(3)$ & $52.847(5)$ \\
1800 & $32788(4)$ & $53.507(6)$ \\
1900 & $38023(5)$ & $54.103(7)$ \\
2000 & $43907(6)$ & $54.642(8)$ \\
2100 & $50498(8)$ & $55.134(9)$ \\
2200 & $57861(10)$ & $55.58(1)$ \\
2300 & $66061(12)$ & $56.00(1)$ \\
2400 & $75169(15)$ & $56.38(1)$ \\
2500 & $85260(19)$ & $56.73(1)$ \\
2600 & $96413(23)$ & $57.06(2)$ \\
2700 & $108709(28)$ & $57.37(2)$ \\
2800 & $122237(34)$ & $57.66(2)$ \\
2900 & $137088(42)$ & $57.92(3)$ \\
3000 & $153358(51)$ & $58.18(3)$ \\
3100 & $171147(62)$ & $58.41(4)$ \\
3200 & $190562(75)$ & $58.63(5)$ \\
3300 & $211713(92)$ & $58.83(6)$ \\
3400 & $234714(111)$ & $59.01(7)$ \\
3500 & $259687(135)$ & $59.18(8)$ \\
3600 & $286757(163)$ & $59.33(9)$ \\
3700 & $316054(197)$ & $59.5(1)$ \\
3800 & $347714(238)$ & $59.6(1)$ \\
3900 & $381877(287)$ & $59.6(1)$ \\
4000 & $418688(347)$ & $59.7(2)$ \\
4100 & $458299(417)$ & $59.8(2)$ \\
4200 & $500863(501)$ & $59.8(2)$ \\
4300 & $546541(600)$ & $59.8(3)$ \\
4400 & $595497(718)$ & $59.7(3)$ \\
4500 & $647900(858)$ & $59.7(4)$ \\
4600 & $703923(1023)$ & $59.6(4)$ \\
4700 & $763743(1218)$ & $59.5(5)$ \\
4800 & $827541(1448)$ & $59.4(6)$ \\
4900 & $895502(1720)$ & $59.2(7)$ \\
5000 & $967815(2043)$ & $59.1(8)$ \\
5100 & $1044671(2424)$ & $58.9(9)$ \\
5200 & $1126265(2878)$ & $59(1)$ \\
5300 & $1212795(3416)$ & $58(1)$ \\
5400 & $1304464(4057)$ & $58(1)$ \\
5500 & $1401474(4820)$ & $58(2)$ \\
5600 & $1504032(5728)$ & $58(2)$ \\
5700 & $1612347(6808)$ & $58(2)$ \\
5800 & $1726633(8091)$ & $57(2)$ \\
5900 & $1847102(9613)$ & $57(2)$ \\
6000 & $1973972(11413)$ & $57(3)$ \\
\hline \hline & &
\end{tabular}


molar fractions are interrelated. Therefore, when determining the uncertainty based on the uncertainties of molar fractions, their covariance matrix should also be considered. An easier way is relating the contribution to the uncertainty of the isobaric heat capacity directly to the uncertainties of the abundances,

$$
\begin{aligned}
& {\left[\left(\frac{\partial x_{16}}{\partial a_{17}} C_{p, 16}+\frac{\partial x_{17}}{\partial a_{17}} C_{p, 17}+\frac{\partial x_{18}}{\partial a_{17}} C_{p, 18}\right)^{2} u_{17}^{2}\right.} \\
& \left.\quad+\left(\frac{\partial x_{16}}{\partial a_{18}} C_{p, 16}+\frac{\partial x_{17}}{\partial a_{18}} C_{p, 17}+\frac{\partial x_{18}}{\partial a_{18}} C_{p, 18}\right)^{2} u_{18}^{2}\right]^{1 / 2}
\end{aligned}
$$

where the partial derivatives are obtained from Eq. (4). This results in the expression

$$
\begin{aligned}
x_{16} \cdot\left\{\left[-C_{p, 16}+\left(1+a_{18}\right) C_{p, 17}-a_{18} C_{p, 18}\right]^{2} u_{17}^{2}\right. & \\
& \left.+\left[-C_{p, 16}-a_{17} C_{p, 17}+\left(1+a_{17}\right) C_{p, 18}\right]^{2} u_{18}^{2}\right\}^{1 / 2} .
\end{aligned}
$$

Table 7 contains the recommended $Q_{\text {int }}(T)$ partition function and the $C_{p}(T)$ of heavy water. We note that the uncertainty which comes from the uncertainties of the abundances (using Eq. (7)) is negligible, as the uncertainties of $Q_{\text {int }}(T)$ and $C_{p}(T)$ are larger by at least two orders of magnitude.

\subsection{Low-temperature limit}

Due to the heavier mass and the larger moments of inertia of heavy water over ordinary water, it behaves less as a quantum system at the lowest temperatures than $\mathrm{H}_{2}{ }^{55,56}$ or $\mathrm{H}_{2}{ }^{16} \mathrm{O} .{ }^{21,57}$ Nevertheless, as Fig. 5 shows the qualitative picture is the same as for $\mathrm{H}_{2}{ }^{16} \mathrm{O}$, just the (nearly) complete equilibration happens at a much lower temperature, below $50 \mathrm{~K}$.

\subsection{On the maximum in $C_{p}$}

Similarly to the case of $\mathrm{H}_{2}{ }^{16} \mathrm{O},{ }^{21}$ Table 7 shows a clear maximum, at about $4100 \mathrm{~K}$, of the $C_{p}(T)$ function of heavy water. As tested, one does not qualitatively change this feature by adding the quasi-bound states to the energy-level set. There is only a shift of the maximum to (slightly) higher T. Quasibound states will make a much bigger contribution than the excited electronic states, as all the low-lying electronic excited states of water are dissociative so they do not contribute in a model with only sums over (quasi-)bound states. Having a maximum in the $C_{p}(T)$ function is a feature and not a problem and it just means that the structure in $C_{p}(T)$ is definitional and due to our choice of treating the various dissociated systems separately.

\section{Summary and Conclusions}

Temperature-dependent ideal-gas internal partition functions, $Q_{\text {int }}(T)$, have been determined, in the range of 0 to $6000 \mathrm{~K}$, for the following molecules: ortho- and para- $\mathrm{D}_{2}{ }^{16} \mathrm{O}$, 


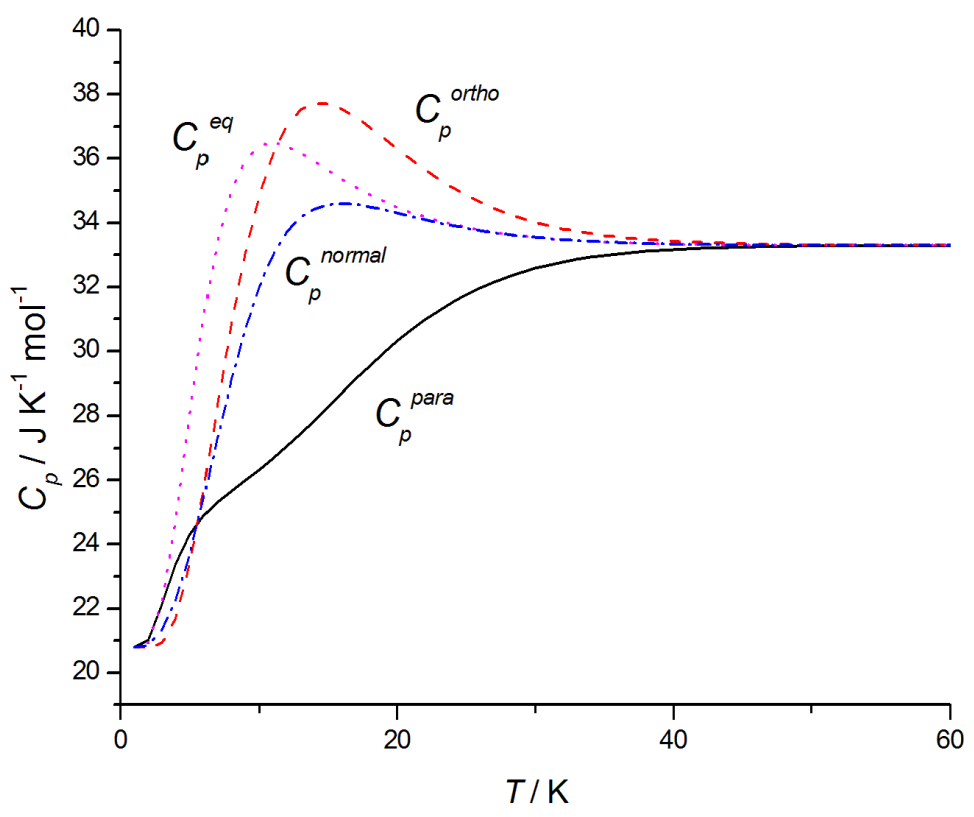

Figure 5. The ortho- $\mathrm{D}_{2}{ }^{16} \mathrm{O}$ (dashed, red curve), the para- $\mathrm{D}_{2}{ }^{16} \mathrm{O}$ (full, black curve), the nuclearspin-equilibrated $\mathrm{D}_{2}{ }^{16} \mathrm{O}$ (magenta, dotted curve), and the normal mixture $\mathrm{D}_{2}{ }^{16} \mathrm{O}$ (blue, dash dotted curve) isobaric heat capacities at low temperatures, below $100 \mathrm{~K}$.

ortho- and para- $\mathrm{D}_{2}{ }^{17} \mathrm{O}$, and ortho- and para- $\mathrm{D}_{2}{ }^{18} \mathrm{O}$. The $Q_{\text {int }}(T)$ values are based on the use of the explicit summation technique. A large number of experimentally known energy levels (12 269, 338, and 3351 for $\mathrm{D}_{2}{ }^{16} \mathrm{O}, \mathrm{D}_{2}{ }^{17} \mathrm{O}$, and $\mathrm{D}_{2}{ }^{18} \mathrm{O}$, respectively) and an almost complete set of first-principles energy levels, over three million for each isotopologue, have been utilized during the explicit summation. These ideal-gas internal partition functions and their first two moments were then employed to obtain the following thermochemical functions in the same temperature range: Gibbs energy function, enthalpy, entropy, and isobaric heat capacity. Approximately two standard deviation uncertainties have also been determined for all these quantities. These uncertainties are much smaller than ever determined before for these molecules. Above about $3000 \mathrm{~K}$ the contribution coming from unbound states gives the largest percentage of the overall uncertainty, while at the highest temperatures the uncertainty in the energy level density is the other factor which significantly affects the overall uncertainties. Following the accepted practice in thermochemistry, nuclear-spinequilibrated thermochemical functions have also been obtained for $\mathrm{D}_{2}{ }^{16} \mathrm{O}, \mathrm{D}_{2}{ }^{17} \mathrm{O}$, and $\mathrm{D}_{2}{ }^{18} \mathrm{O}$. These functions were then combined to provide partition and caloric functions for heavy water, defined according to the IAPWS convention. All the data obtained are given in the supplementary material with $1 \mathrm{~K}$ increments.

Four sources of uncertainty of the values of the thermochemical functions determined have been identified, namely the uncertainty of the energy levels, the uncertainty of the number of energy levels (this becomes an issue close to dissociation), the approximate consideration of 
the effect of unbound states, and the uncertainty of the physical constants employed. At this point it must also be mentioned that "real" heavy water, especially as used in industry, might not match the "official" VSMOW oxygen isotope abundances. The procedures for purifying heavy water typically also make the oxygen abundances a little "heavier", but this is almost never measured. Thus, this is an additional (small) source of uncertainty in applying the "heavy water" heat capacities determined in this study to real systems. The isotopologuedependent data presented here allows users to construct accurate thermodynamic data for other compositions as needed.

The large amount of data supplied in this study should serve well the purposes of the International Association for the Properties of Water and Steam (IAPWS) seeking to produce a new Equation of State (EOS) for heavy water, replacing their 1984 recommendation, slightly revised in 2005, based on ideal-gas data obtained in 1954 by Friedman and Haar (FH). ${ }^{15}$ The $\mathrm{FH}$ data form also the basis of the JANAF tables of heavy water. ${ }^{18}$ Replacing the IAPWS and JANAF data with the new, high-quality data of the present study is highly recommended.

\section{Acknowledgments}

The authors are grateful to the COST action "Molecules in Motion" (MOLIM, CM1405) for support. A.G.C. thanks the NKFIH (grant number K119658) for supporting the work performed in Hungary. J.H. acknowledges support provided by the Czech Science Foundation (grant no. 16-02647S). N.F.Z. thanks the Russian Fund for Basic Research for their support. R.R.G. acknowledges support by the National Science Foundation through Grant No. AGS-1622676. The authors are grateful to Dr. Allen Harvey for many useful discussions concerning the topic of this paper.

\section{References}

${ }^{1}$ H. M. Butner, S. B. Charnley, C. Ceccarelli, S. D. Rodgers, J. R. Pardo, B. Parise, J. Cernicharo, and G. R. Davis, Astrophys. J. 659, L137 (2007).

${ }^{2}$ K. Furuya, E. F. van Dishoeck, and Y. Aikawa, Astron. Astrophys. 586, A127 (2016).

${ }^{3}$ C. Vastel, C. Ceccarelli, E. Caux, A. Coutens, J. Cernicharo, S. Bottinelli, K. Demyk, A. Faure, L. Wiesenfeld, Y. Scribano, A. Bacmann, P. Hily-Blant, S. Maret, A. Walters, E. A. Bergin, G. A. Blake, A. Castets, N. Crimier, C. Dominik, P. Encrenaz, M. Gerin, P. Hennebelle, C. Kahane, A. Klotz, G. Melnick, L. Pagani, B. Parise, P. Schilke, V. Wakelam, A. Baudry, T. Bell, M. Benedettini, A. Boogert, S. Cabrit, P. Caselli, C. Codella, C. Comito, E. Falgarone, A. Fuente, P. F. Goldsmith, F. Helmich, T. Henning, E. Herbst, T. Jacq, M. Kama, W. Langer, B. Lefloch, D. Lis, S. Lord, A. Lorenzani, D. Neufeld, B. Nisini, S. Pacheco, J. Pearson, T. Phillips, M. Salez, P. Saraceno, K. Schuster, X. Tie- 
lens, F. van der Tak, M. H. D. van der Wiel, S. Viti, F. Wyrowski, H. Yorke, P. Cais, J. M. Krieg, M. Olberg, and L. Ravera, Astron. Astrophys. 521, L31 (2010).

${ }^{4}$ A. Coutens, J. K. Jorgensen, M. V. Persson, E. F. van Dishoeck, C. Vastel, and V. Taquet, Astrophys. J. Lett. 792, L5 (2014).

${ }^{5}$ Z. Awad, S. Viti, E. Bayet, and P. Caselli, Mon. Not. Royal Astron. Soc. 443, 275 (2014).

${ }^{6}$ A. J. Hewitt, N. Doss, N. F. Zobov, O. L. Polyansky, and J. Tennyson, Mon. Not. R. Astron. Soc. 356, 1123 (2005).

7 "http://www.iapws.org/: IAPWS is an international non-profit association of national organizations concerned with the properties of water and steam, particularly thermophysical properties, cycle chemistry guidelines, and other aspects of high-temperature steam, water and aqueous mixtures relevant to thermal power cycles and other industrial and scientific applications,".

${ }^{8}$ International Association for the Properties of Water and Steam, "IAPWS G5-01(2016), Guideline on the Use of Fundamental Physical Constants and Basic Constants of Water," (2016).

${ }^{9}$ R. Gonfiantini, Nature 271, 534 (1978).

${ }^{10}$ National Institute of Standards and Technology, "Report of Investigation, Reference Materials 8535, 8536, and 8537," (2005).

${ }^{11}$ National Institute of Standards and Technology, "Report of Investigation, Reference Material 8535a," (2011).

${ }^{12}$ P. G. Hill, R. D. MacMillan, and V. Lee, Tables of Thermodynamic Properties of Heavy Water in SI Units (AECL 7531, 1981).

${ }^{13}$ P. G. Hill, R. D. C. McMillan, and V. Lee, J. Phys. Chem. Ref. Data 11, 1 (1982).

${ }^{14}$ S. Kaizerman, E. Wacholder, and N. Tomerian, Nucl. Eng. Des. 80, 385 (1984).

${ }^{15}$ A. S. Friedman and L. Haar, J. Chem. Phys. 22, 2051 (1954).

${ }^{16}$ International Association for the Properties of Water and Steam, "IAPWS R3-84(2005), Revised Release on the IAPS Formulation 1984 for the Thermodynamic Properties of Heavy Water Substance," (2005).

${ }^{17}$ H. Preston-Thomas, Metrologia 27, 3 (1990).

${ }^{18} \mathrm{M}$. W. Chase, NIST-JANAF Thermochemical Tables, 4th Ed., Journal of Physical and Chemical Reference Data Monograph No. 9 (American Institute of Physics, 1998).

${ }^{19}$ E. R. Cohen and B. N. Taylor, J. Phys. Chem. Ref. Data 2, 663 (1978).

${ }^{20}$ D. A. McQuarrie, Statistical Mechanics (University Science Books, Sausalito, 2000).

${ }^{21}$ T. Furtenbacher, T. Szidarovszky, J. Hrubý, A. A. Kyuberis, N. F. Zobov, O. L. Polyansky,

J. Tennyson, and A. G. Császár, J. Phys. Chem. Ref. Data 45, 043104 (2016).

${ }^{22}$ J. Tennyson, P. F. Bernath, L. R. Brown, A. Campargue, A. G. Császár, L. Daumont, R. R. Gamache, J. T. Hodges, O. V. Naumenko, O. L. Polyansky, L. S. Rothmam, A. C. Vandaele, N. F. Zobov, N. Dénes, A. Z. Fazliev, T. Furtenbacher, I. E. Gordon, S.-M. Hu, T. Szidarovszky, and I. A. Vasilenko, J. Quant. Spectrosc. Radiat. Transf. 142, 93 (2014). 
${ }^{23}$ J. M. L. Martin, J. P. Francois, and R. Gijbels, J. Chem. Phys. 96, 7633 (1992).

${ }^{24}$ A. J. Hewitt, N. Doss, N. F. Zobov, O. L. Polyansky, and J. Tennyson, Mon. Not. R. Astron. Soc. 356, 1123 (2005).

25 "http://spectra.tsu.ru/partfun/," (2016).

${ }^{26}$ A. G. Császár, C. Fábri, T. Szidarovszky, E. Mátyus, T. Furtenbacher, and G. Czakó, Phys. Chem. Chem. Phys. 13, 1085 (2012).

${ }^{27}$ A. G. Császár, G. Czakó, T. Furtenbacher, and E. Mátyus, Ann. Rep. Comp. Chem. 3, 155 (2007).

${ }^{28}$ T. Furtenbacher, A. G. Császár, and J. Tennyson, J. Mol. Spectrosc. 245, 115 (2007).

${ }^{29}$ T. Furtenbacher and A. G. Császár, J. Quant. Spectrosc. Radiat. Transfer 113, 929 (2012).

${ }^{30}$ S. V. Shirin, N. F. Zobov, and O. L. Polyansky, J. Quant. Spectrosc. Rad. Transfer 109, 549 (2008).

${ }^{31}$ O. L. Polyansky, A. A. Kyuberis, L. Lodi, J. Tennyson, R. I. Ovsyannikov, N. Zobov, and S. N. Yurchenko, Mon. Not. R. Astron. Soc. (2016).

32 "http://www.respecth.hu/," (2016).

${ }^{33}$ J. Tennyson, P. F. Bernath, L. R. Brown, A. Campargue, M. R. Carleer, A. G. Császár, L. Daumont, R. R. Gamache, J. T. Hodges, O. V. Naumenko, O. L. Polyansky, L. S. Rothmam, A. C. Vandaele, N. F. Zobov, A. R. Al Derzi, C. Fábri, A. Z. Fazliev, T. Furtenbacher, I. E. Gordon, L. Lodi, and I. I. Mizus, J. Quant. Spectrosc. Radiat. Transf. 117, 29 (2013).

${ }^{34}$ J. Tennyson, P. F. Bernath, L. R. Brown, A. Campargue, M. R. Carleer, A. G. Császár, R. R. Gamache, J. T. Hodges, A. Jenouvrier, O. V. Naumenko, O. L. Polyansky, L. S. Rothman, R. A. Toth, A. C. Vandaele, N. F. Zobov, L. Daumont, A. Z. Fazliev, T. Furtenbacher, I. E. Gordon, S. N. Mikhailenko, and S. V. Shirin, J. Quant. Spectrosc. Radiat. Transf. 110, 573 (2009).

${ }^{35}$ J. Tennyson, P. F. Bernath, L. R. Brown, A. Campargue, M. R. Carleer, A. G. Császár, L. Daumont, R. R. Gamache, J. T. Hodges, O. V. Naumenko, O. L. Polyansky, L. S. Rothman, R. A. Toth, A. C. Vandaele, N. F. Zobov, A. Z. Fazliev, T. Furtenbacher, I. E. Gordon, S. N. Mikhailenko, and B. A. Voronin, J. Quant. Spectrosc. Radiat. Transf. 111, 2160 (2010).

${ }^{36}$ J. Tennyson, P. F. Bernath, L. R. Brown, A. Campargue, A. G. Császár, L. Daumont, R. R. Gamache, J. T. Hodges, O. V. Naumenko, O. L. Polyansky, L. S. Rothman, A. C. Vandaele, and N. F. Zobov, Pure Appl. Chem. 86, 71 (2014).

${ }^{37}$ H. W. Kroto, Molecular Rotation Spectra (Dover, New York, 1992).

${ }^{38}$ T. Szidarovszky, A. G. Császár, and G. Czakó, Phys. Chem. Chem. Phys. 12, 8373 (2010).

${ }^{39}$ J. Tennyson, M. A. Kostin, P. Barletta, G. J. Harris, O. L. Polyansky, J. Ramanlal, and N. F. Zobov, Comput. Phys. Commun. 163, 85 (2004).

${ }^{40}$ O. V. Boyarkin, M. A. Koshelev, O. Aseev, P. Maksyutenko, T. R. Rizzo, N. F. Zobov, L. Lodi, J. Tennyson, and O. L. Polyansky, Chem. Phys. Lett. 568-569, 14 (2013). 
${ }^{41}$ D. S. Underwood, J. Tennyson, S. N. Yurchenko, X. Huang, D. W. Schwenke, T. J. Lee, S. Clausen, and A. Fateev, Mon. Not. R. Astron. Soc. 459, 3890 (2016).

${ }^{42}$ J. Tennyson and S. N. Yurchenko, Intern. J. Quantum Chem. , (in press) (2016).

${ }^{43}$ A. Dora, L. Bryjko, T. van Mourik, and J. Tennyson, J. Chem. Phys. 130, 164307 (2009).

${ }^{44}$ J. E. Mayer and M. G. Mayer, Statistical Mechanics (Wiley, New York, 1940).

${ }^{45}$ G. Herzberg, Molecular Spectra and Molecular Structure. II. Infrared and Raman Spectra of Polyatomic Molecules (Van Nostrand Co., New York, 1960).

${ }^{46}$ G. N. Lewis, M. Randall, K. S. Pitzer, and L. Brewer, Thermodynamics (McGraw-Hill, New York, 1961).

${ }^{47}$ F. V. Prudente and A. J. C. Varandas, J. Phys. Chem. A 106, 6193 (2002).

${ }^{48}$ A. G. Császár and T. Furtenbacher, J. Mol. Spectrosc. 266, 99 (2011).

${ }^{49}$ T. Furtenbacher and A. G. Császár, J. Mol. Struct. 1009, 123 (2012).

${ }^{50}$ P. J. Mohr, D. B. Newell, and B. Taylor, J. Phys. Chem. Ref. Data 45, 043102 (2016).

51 "See supplementary material at [url to be inserted] for a derivation of Eq. (3) and for listings of various temperature-dependent thermochemical quantities, both with and without estimated contributions for unbound states," (2017).

${ }^{52}$ G. S. Kell, J. Phys. Chem. Ref. Data 6, 1109 (1977).

${ }^{53}$ P. Baertschi, Earth and Planetary Science Letters 31, 341 (1976).

${ }^{54}$ W. Li, B. Ni, D. Jin, and T. L. Chang, Kexue Tongbao (Chinese Science Bulletin) 33, 1610 (1988).

${ }^{55}$ D. M. Dennison, Proc. Roy. Soc. A 115, 483 (1927).

${ }^{56}$ K. F. Bonhoeffer and P. Harteck, Z. Physik. Chem. 4B, 113 (1929).

${ }^{57}$ C. C. Stephenson and H. O. McMahon, J. Chem. Phys. 7, 614 (1939). 